\title{
Development and Validation of a Novel Multiplexed DNA Analysis System,
}

\section{InnoTyper $^{\circledR} 21$}

Hiromi Brown ${ }^{1}$, Robyn Thompson ${ }^{1}$, Gina Murphy ${ }^{1}$, Dixie Peters ${ }^{2}$, Bobby La Rue ${ }^{2,3}$, Jonathan King ${ }^{2}$, Anne H

Montgomery $^{1}$, Marion Carroll ${ }^{1}$, James Baus ${ }^{1}$, Sid Sinha $^{1}$, Frank R Wendt ${ }^{2}$, Bing Song ${ }^{2}$, Ranajit Chakraborty ${ }^{2}$, Bruce

Budowle $^{2,4}$ and Sudhir K Sinha ${ }^{1 *}$

1. InnoGenomics Technologies, LLC, 1441 Canal Street, Suite 307, New Orleans, Louisiana 70112

2. Center for Human Identification, University of North Texas Health Science Center, 3500 Camp Bowie Boulevard, Fort Worth, Texas 76107

3. Department of Forensic Science, Sam Houston State University, 1003 Bower's Boulevard, Huntsville, TX 77340

4. Center of Excellence in Genomic Medicine Research (CEGMR), King Abdulaziz University, Jeddah, Saudi Arabia 


\section{Introduction}

Forensic DNA testing methodology has seen several improvements and innovation in recent years, mainly increased number of loci in a single multiplex for high discrimination power and utilization of massively parallel sequencing methodology [1-3]. Short tandem repeat (STR) loci are the primary genetic markers used in human identity testing. These markers are highly polymorphic and afford a high degree of sensitivity of detection such that relatively low quantities (e.g., 100 picograms) of template DNA can be analyzed [4-8]. However, one of the limitations of STR markers is that the amplicon size of some of these markers can be greater than 200 base pairs (bp), even up to 400-600 bp, which can make it difficult to type highly degraded samples. In recent years several STR multiplexes have been designed with reduced amplicon sizes for such applications (i.e., the so-called mini-STRs) [9, 10]. However, only a few STR markers can be simultaneously designed with amplicon sizes less than 150 bp to be more suitable for typing highly degraded samples, and run together on current capillary electrophoresis instruments. For highly degraded samples, mitochondrial DNA (mtDNA) is typically used [11, 12]. However, current mtDNA analysis is laborious and expensive, few forensic laboratories currently have mtDNA typing capabilities, and, due to a lack of recombination, its power of discrimination is low.

Single nucleotide polymorphisms (SNPs) and insertion/deletion polymorphisms (InDels) have been investigated as an alternative to STRs to analyze highly degraded DNA [13, 33-35]. These markers can be detected in shorter amplicons and have low mutation rates. A type of marker similar in nature to InDels is retrotransposable element (such as $A l u$ ) insertion polymorphisms, or INNULs (for insertion/null) [16]. INNULs are highly abundant in the human genome and extremely stable once inserted. These markers can be useful for human identity testing [14-21]. 
The INNUL polymorphism is based on the presence and absence of retrotransposable elements (REs) which consist of long interspersed nuclear elements (LINEs) and short interspersed nuclear elements (SINEs). SINEs were originally defined by their interspersed nature and length (75-500bp). LINE full-length elements are $\sim 6 \mathrm{~kb}$ in length, contain an internal promoter for polymerase II, two open reading frames (ORFs), and end in a polyA-tail [15]. Ustyugova et al [22] demonstrated that REs could be used for cell line identification. Mamedov et al [21] and Novick et al [24] described a set of Alus (a type of SINE) for paternity testing. Both of these studies intimated that the systems could be applied to forensic analyses. The lack of, or very minimal, mutation rate in Alus [25] compared to STR systems [26] makes an Alu based genotyping system appealing for kinship analyses compared with the less stable STRs. In addition, Alu based systems do not yield stutter artifacts due to slippage during the PCR as seen with STRs [1-4]. Although REs make up over 40\% of the human genome [27] and present myriad potential targets for human identity testing, these INNULS have received limited attention for use in forensic human identity testing.

The most likely reason for a lack of interest is that the insertion alleles are quite different in size from the null state and thus the alleles are susceptible to preferential amplification and effects of DNA degradation. Forensic samples are often compromised in quality and quantity. Degraded samples may contain fragments of DNA that are less than $165 \mathrm{bp}$ in length and the quantities may be limited to sub-nanogram levels of recoverable DNA [28-31]. REs can range in size from hundreds (SINEs) to several thousand (LINEs) bp in length [14-21]. Previous attempts to use $A l u$ sequences for identity testing capitalized on the size difference between insertion and null alleles by amplifying the entire region with the same forward and reverse primers [24]. The insertion allele would be 200-400 bp larger than the null allele and could be detected by electrophoresis based on size differences. While useful for paternity testing and some population 
studies where DNA is not limited or compromised, the large size difference between amplicons of the no-insertion (null) and insertion alleles will impact amplification efficiency and increase allele dropout during the PCR, which is a limitation for forensic samples (i.e., preferential amplification favoring the smaller allele amplicon and degradation possibly causing drop-out of the insertion allele). Thus, the use of REs as a multiplexed marker system has not been embraced for the analysis of forensic samples [32].

To overcome the multiplexing difficulties due to allele size differences, the unique sequences of the $A l u$ insertion were exploited to detect the presence or absence of $A l u$ insertion at a given genomic position $[17,18]$. One unique property of these REs is a direct repeat sequence at the beginning of $A l u$ insertion and at the end of $A l u$ element called target site duplication (TSD) $[16,17]$. Figure 1 shows the primer design strategies employed to design a highly efficient multiplexed amplification system of 20 retrotransposon insertion polymorphisms and Amelogenin. Utilizing this strategy, one can design primers to create very small amplicons to type highly degraded DNA samples regardless of the size of Alu insertion [17, 18].

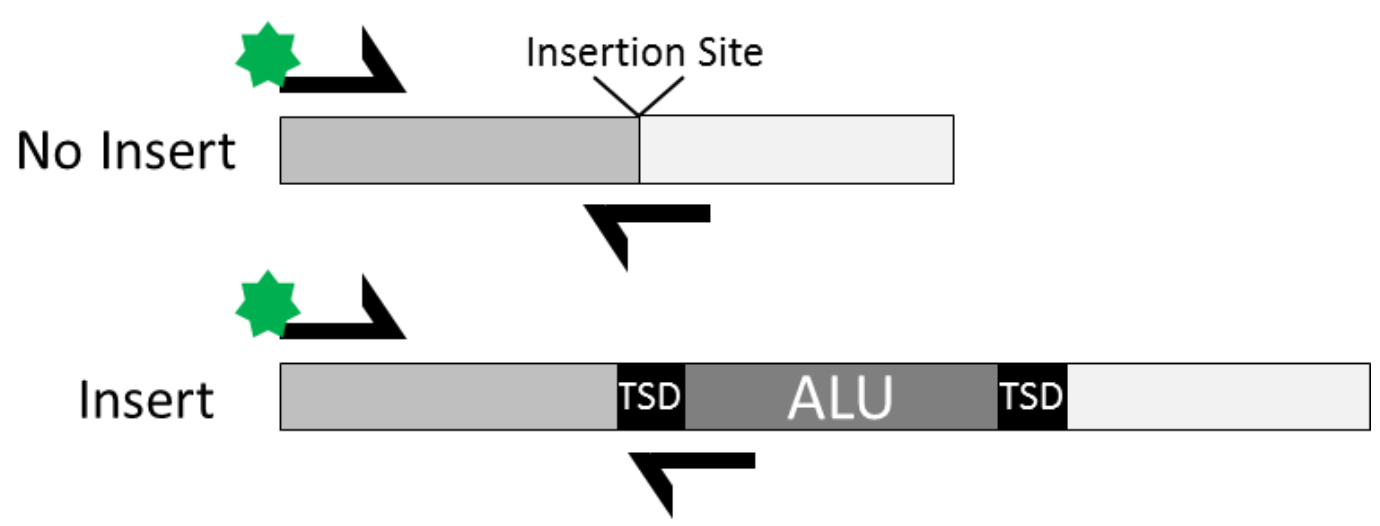

Figure 1. Primer design strategy to type insert and native (or null) alleles with similar but not exact amplicon size differences between the two allelic states. The strategy employs a common forward primer with fluorescent label at $5^{\prime}$ end and two specific reverse primers to amplify either insertion allele or null allele or both in the case of a heterozygote individual. 
The design, performance, and developmental validation of InnoTyper ${ }^{\circledR} 21$ system are described below. The results show that the INNUL system can enhance capabilities for typing biological evidence and, in particular, highly compromised samples.

\section{Materials and Methods}

\section{Fluorophore Selection and Matrix Standard}

The InnoTyper 21 Human Identification kit uses a five-dye chemistry for amplicon detection which is compatible with Applied Biosystems ${ }^{\circledR}$ Genetic Analyzers. Proper spectral calibration is critical to evaluate multicolor systems with the Applied Biosystems Genetic Analyzers. The IGT 5-Dye Matrix Standard (InnoGenomics Technologies) consists of DNA fragments labeled with the fluorescent dyes: $\mathrm{FAM}^{\mathrm{TM}}$, JOE, TMR, ROX, and TGI-ORANGE. These matrix fragments are used on the Applied Biosystems 3130, 3130xL, 3500 or 3500xL Genetic Analyzers to perform a spectral calibration on dye set G5. Once generated, this file is applied during sample detection to calculate the spectral overlap between the five different dyes and separate the raw fluorescent signals into individual dye signals. The IGT 5-Dye Matrix Standard was developed for use with the 5-dye InnoTyper 21 System.

\section{ILS-155 Internal Lane Standard}

ILS-155 (InnoGenomics Technologies) contains eleven single stranded DNAs with the TGI-Orange fluorophore attached. The fragments are 55, 60, 70, 85, 95, 105, 115, 125, 135, 145, and 155 base pairs in size. There are two fragments smaller and three fragments larger in size than the smallest and largest InnoTyper 21 alleles, respectively, which allow using the Local

Southern method for size calling with GeneMapper ${ }^{\circledR}$, GeneMapper ${ }^{\circledR}$ ID and GeneMapper ${ }^{\circledR} I D-X$ software (Applied Biosystems).

\section{Primer Design}


Primers were designed using Primer3 (input version 0.4.0, http://frodo.wi.mit.edu/primer3/). A set of three primers were designed for each marker: one forward primer and two reverse primers, one for the insertion and one for the null allele. The primer design strategies to obtain small amplicons were reported earlier $[16,17]$. The sex determining marker, Amelogenin, consists of one labeled forward primer and one unlabeled reverse primer. All the designed primers have $\mathrm{T}_{\mathrm{m}}$ values in the range of $55-65^{\circ} \mathrm{C}$. To obtain reverse complement information, the program Reverse Complement was used from the Harvard Medical Technology Group and Lipper Center for Computational Genomics (arep.med.harvard.edu/). Subsequently, the primers were screened against the GenBank nonredundant database to determine if they were unique DNA sequences.

\section{Marker selection}

Markers were selected from existing literature and through BLAST sequence analysis [14-24, 38-42]. After initial selection, the potential loci were assessed for suitability for primer design using Primer 3 software [41]. Utilizing the above described primer design strategy, the markers were first evaluated by gel electrophoresis for amplification efficiency, formation of single amplicon and also allele frequency on a set of 25 genomic DNA samples. Chromosomal location and distance were also considered for marker selection. The selected markers were distributed throughout the genome at different chromosomes or a different arm of the same chromosome. Only three sets of markers AC2265 / AC2305, MLS09 / TARBP and AC1141 / NBC51 are on the same arm of the same chromosome, but they are far apart (see Table 1 for chromosomal location). After extensive evaluation [16], twenty Alu markers plus Amelogenin were selected for the InnoTyper 21 multiplex (Table 1). 
Table 1. Selected twenty Alu markers and Amelogenin in the InnoTyper 21 kit. Marker AC4027 is from hg16 human genome; remaining markers are from hg18 human genome.

\begin{tabular}{|c|c|c|c|c|c|}
\hline Marker & $\begin{array}{c}\text { Florescence } \\
\text { Dye }\end{array}$ & Chromosome & Band & Location & Gene ID \\
\hline AC4027 & FAM & 7 & $7 \mathrm{q} 21.11$ & chr7:82559246-82559572 & AC004027.1; 997_1332del \\
\hline MLS26 & FAM & 3 & $3 \mathrm{p} 22.1$ & chr3:40216628-40216628 & Ya5-MLS26; RIP_Alu_chr3_040_01 \\
\hline ALU79712 & FAM & 20 & 20p 12.2 & chr20:11465280-11465588 & 79712; RIP_Alu_chr20_011_01 \\
\hline NBC216 & FAM & 7 & $7 \mathrm{p} 14.1$ & chr7:38474999-38475312 & Ya5NBC216; 4601; Ya5505; RIP_Alu_chr7_038_01 \\
\hline NBC106 & FAM & 21 & $21 \mathrm{q} 22.2$ & chr21:40508751-40509060 & Yb8NBC106; RIP_Alu_chr21_040_01 \\
\hline RG148 & JOE & 2 & $2 q 23.3$ & chr2:150467557-150467867 & Yc1RG148; RIP_Alu_chr2_150_03 \\
\hline $\mathrm{NBC} 13$ & JOE & 16 & $16 \mathrm{p} 12.1$ & chr16:26515540-26515866 & pAlu 16-26535378; Yb8NBC13; RIP_Alu_chr16_026_02 \\
\hline AC2265 & JOE & 13 & $13 \mathrm{q} 33.1$ & chr13:102807866-102808174 & RIP_Alu_chr13_102_01 \\
\hline MLS09 & JOE & 1 & $1 q 25.3$ & chr1:179124190-179124190 & Ya5-MLS09; RIP_Alu_chr1_177_01 \\
\hline AC1141 & TAMRA & 3 & $3 q 11.2$ & chr3:96598900-96599212 & Yb8AC1141; pAlu3-96397335; RIP_Alu_chr3_096_01 \\
\hline TARBP & TAMRA & 1 & $1 q 42.2$ & $\operatorname{chr} 1: 234,527,060-234,614,849$ & AL136124.10; 33110_33420Sdel \\
\hline AMEL & TAMRA & $\mathrm{X}, \mathrm{Y}$ & Xp22.1-22.3 Yp11.2 & & AL137015.9; 46641_46955del \\
\hline AC2305 & TAMRA & 13 & $13 \mathrm{q} 13.3$ & chr13:38926483-38926791 & Ya5ac2305; RIP_Alu_chr13_038_01 \\
\hline HS4.69 & TAMRA & 5 & $5 q 34$ & chr5:164366293-164366709 & NT_023133 \\
\hline NBC51 & TAMRA & 3 & $3 q 28$ & chr3:191773344-191773631 & Ya5NBC51; Ya5NBC345; RIP_Alu_chr3_191_01 \\
\hline ACA1766 & ROX & 8 & $8 \mathrm{q} 12.1$ & chr8:61367553-61367857 & Ya5ACA1766; RIP_Alu_chr8_061_01 \\
\hline NBC120 & ROX & 22 & $22 q 11.21$ & chr22:16427377-16427718 & Yb8NBC120; RIP_Alu_chr22_016_04 \\
\hline $\mathrm{NBC} 10$ & ROX & 4 & $4 \mathrm{q} 31.21$ & chr4:144792753-144793064 & Yb9NBC10; RIP_Alu_chr4_144_01 \\
\hline $\mathrm{NBC} 102$ & ROX & 17 & $17 \mathrm{q} 23.3$ & chr17:58919634-58919634 & Ya5NBC102; Ya5ACE; RIP_Alu_chr17_058_01 \\
\hline SB19.12 & ROX & 19 & $19 q 13.43$ & chr19:61803374-61803676 & Sb19.12; RIP_Alu_chr19_061_01 \\
\hline NBC148 & ROX & 14 & $14 \mathrm{q} 31.1$ & chr14:80666808-80667112 & Yb8NBC148; RIP_Alu_chr14_080_02 \\
\hline
\end{tabular}

\section{Primer Set Optimization}

The allele sizes of InnoTyper 21 range from approximately 63 bp to $123 \mathrm{bp}$. Twenty-one markers are distributed into four dye channels (blue, green, yellow, and red) in a way that no marker overlaps another within one channel and that the two sister alleles sit adjacent to each other (Figure 2). Initially, single-plex reactions composed of one forward and two reverse primers for each selected marker were carried out to ensure locus-specific amplification. Then multiplex reactions were optimized through primer melting temperatures, primer concentration adjustment and empirical performance testing. Twenty-two DNA samples were amplified at 500 pg to evaluate peak heights and peak height ratios of heterozygous alleles. Non-template controls were amplified in triplicate to evaluate formation of primer-dimer peaks in the range of $60-130$ bp.

\section{Creation of Allelic Ladder}


In order to create a consistent source of target DNA for manufacturing of the allelic ladder, each individual allele was amplified and cloned using Thermo Scientific CloneJet PCR Cloning Kit as per manufacturer's recommended procedure. The PCR products obtained by amplifying genomic DNA from homozygote individuals were used to set up the ligation reaction along with the cloning vector, pJET1.2/blunt, T4 DNA Ligase, reaction buffer and water. The reaction mixture was used directly for transformation. Transformation of the circular plasmid DNA into chemically competent $E$. coli cells was performed, and the LB agar plate containing ampicillin was incubated overnight at $37^{\circ} \mathrm{C}$. Four to six clones were selected for screening. Sequencing primers included with the CloneJet PCR Cloning Kit were used to set up PCR amplification, and the amplified products were analyzed on a $2 \%$ agarose gel for the presence of an insert. Using the Zyppy Plasmid Miniprep Kit from Zymo Research Corp, Irvine, CA 92614, U.S.A., plasmid DNA was isolated. The purified plasmid DNA containing cloned portions of the allelic ladder were verified by DNA sequencing. Amplified products from these plasmid DNAs were mixed in appropriate amounts to create the allelic ladder for InnoTyper 21.

The allelic ladder consists of 40 different INNUL alleles as well as Amelogenin X and Y. Figure 2 shows the InnoTyper 21 allelic ladder. The peaks labeled "I" are the insertion alleles and "N" are the null (i.e., no insertion) alleles. In all instances, primer design optimization resulted in the insertion allele having a smaller size than the no-insertion allele, except for markers NBC51 and NBC102, where optimal primer design resulted in the no-insertion allele smaller than the insertion allele. 


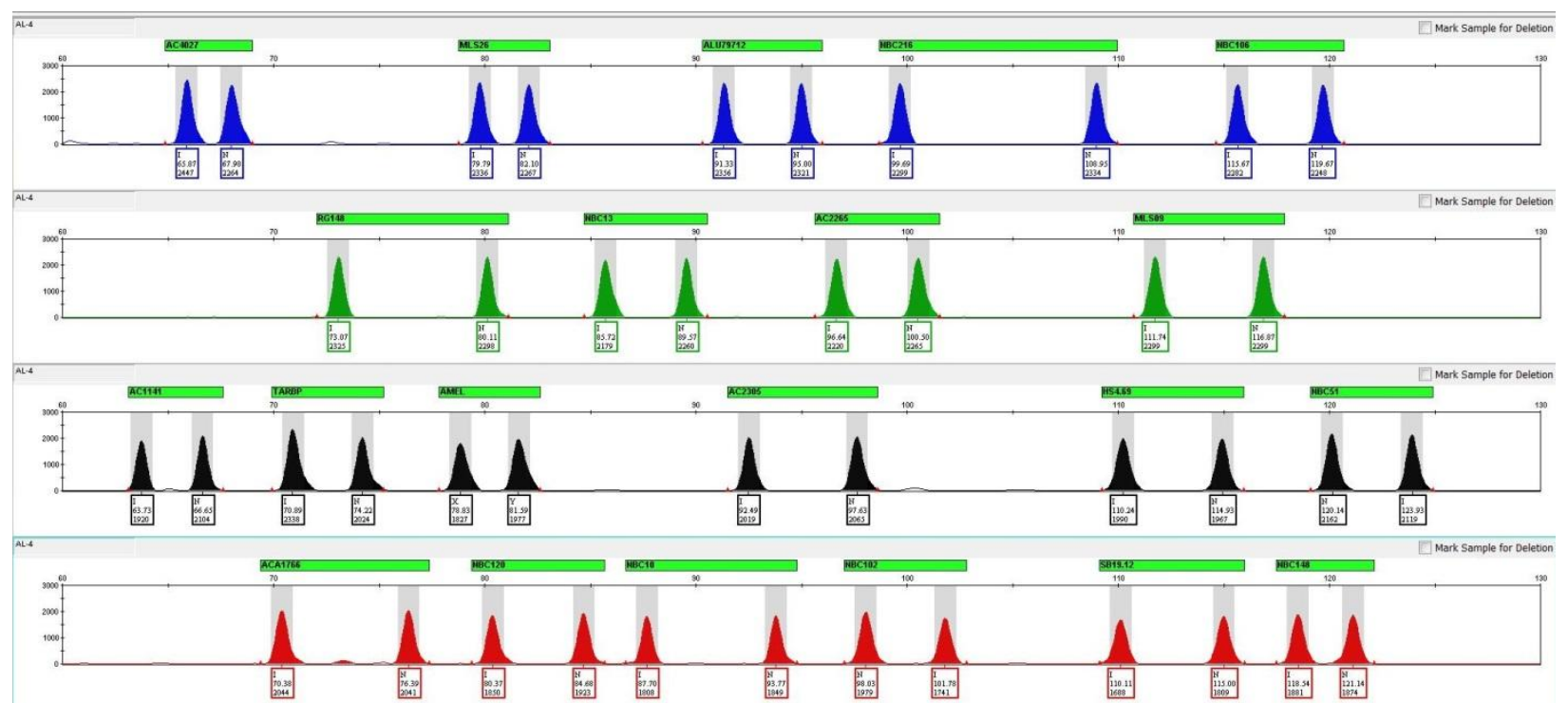

Figure 2. InnoTyper 21 Allelic Ladder showing locus and allele configuration.

\section{Optimization of PCR Components}

The components of InnoTyper 21 PCRs are dNTPs, monovalent salt, $\mathrm{Mg}^{2+}$, carrier proteins, hot start DNA polymerase, sodium azide, Tween 20, and DMSO. Each of these components was tested at a series of concentrations individually to determine the optimal concentrations of each. Pristine DNA samples were amplified in triplicate at $100 \mathrm{pg}, 50 \mathrm{pg}$, and $25 \mathrm{pg}$ (data not shown) and evaluated for peak heights and profile recoveries, and three nontemplate controls were amplified in each condition for the evaluation of primer-dimer formation within the marker region (60 bp to $130 \mathrm{bp}$ ).

\section{Optimization of Thermal Cycling Conditions}

Optimal thermal cycling conditions should generate sufficient sample peak heights while minimizing the occurrence of off-scale allele peaks or allelic dropout events. The thermal cycling parameters of InnoTyper 21 were examined to determine the optimal performance conditions on a GeneAmp ${ }^{\circledR}$ PCR system 9700 with a gold plated silver block using the 9600 emulation mode (Applied Biosystems). The tested parameters were cycle number $(31,32,33$, and 34 cycles), annealing temperature $\left(58^{\circ} \mathrm{C}, 59^{\circ} \mathrm{C}\right.$, and $\left.60^{\circ} \mathrm{C}\right)$, and elongation temperature $\left(60^{\circ} \mathrm{C}, 65^{\circ} \mathrm{C}\right.$, and 
$72^{\circ} \mathrm{C}$ ). At least three non-template controls were amplified in each condition for the evaluation of baseline, artifacts, and primer-dimer formation within the marker region (60 bp to $130 \mathrm{bp}$ ). The optimal conditions were selected by amplifying pristine DNA samples in triplicate at $50 \mathrm{pg}$ and evaluated for peak heights and degrees of profile recoveries. From this study, the standard thermal cycling conditions for InnoTyper 21 was determined to be $95^{\circ} \mathrm{C}$ for 15 minutes (enzyme activation), followed by 31 cycles of denaturation at $95^{\circ} \mathrm{C}$ for 30 seconds, annealing at $58^{\circ} \mathrm{C}$ for 30 seconds, and extension at $72^{\circ} \mathrm{C}$ for 60 seconds, and then the final extension at $60^{\circ} \mathrm{C}$ for 60 minutes with a $4^{\circ} \mathrm{C}$ temperature hold. These parameters are set to yield high sensitivity of detection from low level samples while minimizing the production of PCR artifacts.

\section{DNA Samples and DNA Extraction}

Anonymous samples used for the validation experiments and control DNA were obtained from The Blood Center (New Orleans), DNA Diagnostic Center (Ohio), Tulane Health Sciences Center (New Orleans), Coriell Institute for Medical Research (New Jersey), and the National Institute of Standards and Technology (Maryland). Extraction methods used include PCIA organic extraction method and ChargeSwitch ${ }^{\circledR}$ Nucleic Acid Purification Technology (Invitrogen). DNA obtained from ATCC (Manassas, VA) was used for the mixture study. Nonprobative sample types included mock rape kit swabs, hair, bone, tooth, blood, semen and saliva samples, as well as degraded and inhibited DNA samples. All extractions were run with a reagent blank. Samples were stored at $-20^{\circ} \mathrm{C}$ until amplification.

\section{Quantification of DNA using Real-Time PCR Amplification}

All human DNA samples were quantified using the InnoQuant ${ }^{\circledR}$ Human DNA Quantification \& Degradation Assessment Kit (InnoGenomics Technologies) [43] on the 7500 Real-Time PCR System (Applied Biosystems). The data were analyzed using the HID RealTime PCR Analysis Software v1.1/1.2 (Applied Biosystems) as described in the InnoQuant ${ }^{\circledR}$ 
Human DNA Quantification \& Degradation Assessment Kit User Guide. Non-human DNA samples were quantified using NanoDrop 2000 UV-Vis Spectrophotometer (Thermo Fisher Scientific).

\section{PCR Amplification}

Unless noted otherwise, InnoTyper 21 amplifications were performed in a reaction volume of $25 \mu \mathrm{L}$ using the standard thermal cycling conditions as described. The final optimized reactions contain $3.5 \mu \mathrm{L}$ of InnoTyper 21 Primer Mix, $5 \mu \mathrm{L}$ of InnoTyper 21 Master Mix, $0.5 \mu \mathrm{L}$ of IGT DNA Polymerase, and a maximum volume of $16 \mu \mathrm{L}$ of target DNA template. VWR ${ }^{\circledR}$ PCR 8-Well Tube Strips (VWR) were used to amplify DNA samples in the GeneAmp® PCR system 9700 with a gold plated silver block (Applied Biosystems). Samples also were typed with the Identifiler ${ }^{\circledR}$ Plus (Thermo Fisher Scientific) [7] and MiniFiler ${ }^{\circledR}$ (Thermo Fisher Scientific) [8] kits following their user manuals. The Identifiler Plus PCR reactions were performed using 29 cycles and the MiniFiler reactions were performed using 30 cycles.

\section{Capillary Electrophoresis}

PCR amplified products were separated and detected on the Applied Biosystems 3130 Genetic Analyzer with POP-4 ${ }^{\mathrm{TM}}$ polymer (Applied Biosystems) using the specified G5 variable binning module as described above in the Fluorophore Selection and Matrix Standard section for InnoTyper 21, as well as the corresponding Identifiler Plus and MiniFiler user guides. For InnoTyper $21,1 \mu \mathrm{L}$ of the amplified product or allelic ladder and $0.2 \mu \mathrm{L}$ of ILS-155 Internal Lane Standard were added to $10.8 \mu \mathrm{L}$ of deionized Hi-Di ${ }^{\mathrm{TM}}$ Formamide (Applied Biosystems), denatured at $95^{\circ} \mathrm{C}$ for 3 minutes, and chilled on ice for 3 minutes. Samples were injected and separated on the Applied Biosystems 3130 using the default "FragmentAnalysis36_POP4_1" Run Module Settings for the 4-capillary 3130 instrument. The data were collected using the Applied Biosystems 3130 Data Collection Software application v3.0. The procedures of sample 
preparations of Identifiler Plus and MiniFiler for capillary electrophoresis were followed as described in their respective user guides.

\section{Data Analysis}

Electrophoresis results were analyzed with GeneMapper ${ }^{\circledR} I D-X$ software v1.1/1.4 or GeneMapper $^{\circledR} 4.0$ by setting the analytical threshold at 50 relative fluorescence units (RFU) for InnoTyper 21, Identifiler Plus, and MiniFiler. The Local Southern size calling method was used to analyze CE results of InnoTyper 21 (the Precision Study data was analyzed with Local Southern, $2^{\text {nd }}$ order, and $3^{\text {rd }}$ order least squares sizing methods), with a baseline window of 30 points. InnoTyper 21 consists of twenty-one bi-allelic markers including Amelogenin. Each Alu marker will produce either a single peak (homozygous insertion or no insertion) or two peaks (heterozygous sister allele peaks). Amelogenin will produce one $\mathrm{X}$ homozygous peak for female samples and $\mathrm{X}$ and $\mathrm{Y}$ peaks for male samples. The maximum number of peaks that could be possible to obtain with InnoTyper 21 is forty two. In this study a profile recovery expressed in percent $(\%)$ is calculated as: a homozygous peak is counted as 2 and each heterozygous sister peak is counted as 1 . The sum of the peaks at 21 markers is then taken and this peak count is divided by the maximum count of 42 and multiplied by 100. Regardless of whether there is a difference in sample genotypes, the total peak count is 42 with a full profile. Partial profiles give a peak count less than 42 . A mean profile recovery is obtained by taking a mean of profile recoveries of three amplification results, and a standard deviation (SD) of the mean also is calculated. A mean peak height of triplicate results was calculated as: first, take a sum of RFU peak heights from each run and divide the sum by the number of peaks detected. The SD of this process was not reported in this study since a homozygous peak height is nearly twice that of a heterozygous allele peak, which produces relatively high SD if a sum of the peak heights were divided by the number of peaks produced. The mean peak height of triplicate results was 
calculated by taking a mean of the three mean peak heights. The SD of this process was reported here. Mean profile recoveries with SDs and mean peak heights with SDs of the Identifiler Plus and MiniFiler results were calculated in a similar manner as InnoTyper 21 results.

\section{Accuracy, Precision, and Reproducibility}

Allelic ladder sizing precision was evaluated from six injections of the ladder run on the Applied Biosystems 3130 Genetic Analyzer. The standard deviation of the mean size of each ladder allele was calculated. Twenty-five DNA samples from twelve Caucasians, twelve African Americans, and the kit control DNA were amplified at $0.5 \mathrm{ng}$ total DNA input in triplicate with the InnoTyper 21 kit and subjected to electrophoresis on the Applied Biosystems 3130 Genetic Analyzer. The genotypes of the obtained profiles from twenty-five DNA samples were compared to their replicate results for reproducibility of the InnoTyper 21 kit. Sample allele sizing was evaluated from the twenty-five DNA sample amplifications in triplicate, which produced a total of 2301 alleles. The results were used to calculate the deviation of the sample allele size from the mean of the allelic ladder allele size.

\section{Species Specificity}

DNA samples from three primates (1 ng each from green monkey, orangutan, and chimpanzee) were subjected to PCR amplification four times each using the InnoTyper21 kit. Five non-primate mammals (5 ng and 10 ng each from cat, dog, deer, rat, and mouse), three nonmammalian species (5 ng and $10 \mathrm{ng}$ each from chicken, fish, and mosquito), and 5 microorganisms (5 ng and/or $10 \mathrm{ng}$ each from Escherichia coli, Saccharomyces cerevisiae, and Staphylococcus aureus and $10 \mathrm{ng}$ each from Ralstonia eutropha and Rhodococcus rubber) were subjected to PCR amplification using the InnoTyper21 kit in duplicate. Species DNA samples were obtained from Coriell (Camden, New Jersey) (orangutan and chimpanzee), AMRESCO (Solon, OH) (fish sperm), the Microbiology Department of Tulane University (New Orleans, 
LA) (Saccharomyces cerevisiae, Staphylococcus aureus, green monkey, mouse, mosquito,), and other DNA sources were obtained internally (Ralstonia eutropha, Rhodococcus rubber, Escherichia coli, cat, dog, deer, chicken, and rat).

\section{Sensitivity Study}

Two DNA samples, NIST SRM 2372 Component A and control DNA 1212, were serially diluted and amplified in triplicate with the InnoTyper 21 kit. The NIST Human DNA Quantitation Standard was used in the sensitivity study as a means of obtaining accurate sample concentrations. Both DNA templates were amplified at 400, 200, 100, 50, 25, 12.5, and $6.25 \mathrm{pg}$. The triplicate results were analyzed for profile recoveries, peak heights, and peak height ratios (PHR). PHR was calculated by dividing the smaller peak height by the larger peak height of heterozygous alleles.

\section{Degradation Study}

A TruSonik TS-2.5L ultrasonic cleaning device was used to mechanically shear DNA samples. The device emits ultrasonic waves at a frequency of $40 \mathrm{KHz}$, was filled with distilled water and set at $60^{\circ} \mathrm{C} .110 \mu \mathrm{L}$ of extracted DNA (sample 285) from blood were sonicated in time increments for up to 20 hours. $10 \mu \mathrm{L}$ of the DNA solution were removed at $0,2,4,6,8$, $11,14,16$, and 20 hours of sonication. The degraded DNA samples were quantified and the extent of degradation was assessed using the InnoQuant ${ }^{\circledR}$ kit (InnoGenomics Technologies). The InnoQuant ${ }^{\circledR}$ kit is a multiplex qPCR system targeting two independent retrotransposon genomic targets to obtain quantification of an 80 bp "short" DNA fragment and a 207 bp "long" DNA fragment in a DNA sample. The ratio of the two quantitation values (short/long) provides a “Degradation Index" (DI), or a semi-quantitative measure of a sample's extent of degradation. The more degraded a DNA sample is, the higher the DI value becomes. The InnoQuant ${ }^{\circledR}$ DI values were used as a measure of a sample's extent of degradation. Nine different levels of the 
degraded DNA (sample 285) with DI values of 0.89, 2.16, 2.48, 13.14, 15.16, 62.42, 66.16, 75.16, and 241.69 were obtained by sonication. $200 \mathrm{pg}$ of each level of the degraded DNA was amplified in triplicate with the InnoTyper 21, Identifiler Plus, and MiniFiler kits. The triplicate results were analyzed for degree of profile recovery and mean peak heights including their standard deviations. The DNA sample with DI of 241.69 was serially diluted and amplified in triplicate with the InnoTyper 21 kit and MiniFiler kits. The triplicate results were analyzed for profile recovery and peak heights.

\section{Inhibition Study}

An inhibition study was performed with hematin (Sigma-Aldrich), humic acid (Alfa Aesar, Ward Hill, MA), and melanin (Sigma-Aldrich) to evaluate performance of the InnoTyper 21 kit in the presence of PCR inhibitors. Hematin is a heme-containing known inhibitor, humic acid is the major organic constituent found in soil, and melanin is a dark pigment occurring in hair and skin. The kit control DNA 1212 (400 pg) was amplified in triplicate in the presence of various concentrations of the inhibitors. Hematin and melanin were prepared at $1 \mathrm{mM}$ and 1

$\mathrm{mg} / \mathrm{mL}$, respectively, in $0.1 \mathrm{~N} \mathrm{NaOH}$. Humic acid was prepared at $500 \mathrm{ng} / \mu \mathrm{L}$ in $\mathrm{TE}^{-4}$ buffer $(10$ $\mathrm{mM}$ Tris at $\mathrm{pH} 8.0,0.1 \mathrm{mM}$ EDTA). Each inhibitor was added to the PCR reaction separately to obtain final concentrations ranging 0 to $10 \mathrm{ng} / \mu \mathrm{L}$ of melanin, 0 to $105 \mu \mathrm{M}$ of hematin, and 0 to $30 \mathrm{ng} / \mu \mathrm{L}$ of humic acid.

\section{Mixture Study}

Although mixtures of human DNA are not normally analyzed in a capillary electrophoresis platform with bi-allelic systems such as InnoTyper 21, DNA profiles originating from more than one individual will sometimes be observed in the analysis. Mixtures may result from contamination, either at a laboratory or prior to the sample arriving at a laboratory, or when samples anticipated to contain mixtures (e.g., touch DNA samples) are processed with InnoTyper 
21. Therefore, experiments were designed to test a variety of mixture ratios with InnoTyper 21 to determine at what ratio the minor component begins to drop out of the profile observed.

A mixture of two pristine DNA samples was amplified in duplicate at various ratios while holding the total amount of DNA input constant at $500 \mathrm{pg}$. The ratios were 1:0 (500 pg:0 pg), 15:1 (469 pg:31 pg), 7:1 (438 pg:62pg), 3:1 (375 pg:125 pg), 1:1 (250 pg: 250pg), and 0:1 (0 $\mathrm{pg}: 500 \mathrm{pg}$ ). The major DNA component is female, and the minor component is male. PHR of the mixtures and PHR of the single source samples (data from accuracy, precision, and reproducibility section) were compared.

\section{Case-Type Samples Study}

Casework-type samples typically encountered in a forensic laboratory were examined to determine if reliable results could be obtained with InnoTyper 21. Samples included male and female samples, samples with known low quantities of DNA, and samples that may be compromised in quantity and/or quality. A total of 39 samples of various types were tested with InnoTyper 21, including blood, hair shafts (i.e. lacking root material), saliva, semen, bone, and teeth. The non-probative casework samples had been genotyped previously with the Identifiler

Plus and Yfiler ${ }^{\circledR}$ systems (Thermo Fisher). Degradation index values obtained from InnoQuant ${ }^{\circledR}$ quantitation kit were evaluated and correlated with profile recovery. Concordance in conclusions between InnoTyper 21 and previously typed systems was evaluated, as well as peak heights and PHRs.

\section{Analysis of highly degraded non-probative human remains}

Highly degraded human remains were analyzed with InnoTyper 21 by performing a sensitivity study with skeletal remains previously tested with STRs and mtDNA, and by testing a set of challenging human remains with no or minimal previous profile data using autosomal STR and mtDNA. DNA extraction for the remains was performed via a demineralization protocol 
followed by PCIA organic extraction method and quantified using the Quantifiler ${ }^{\circledR}$ Duo DNA Quantification Kit (Thermo Fisher). The samples were amplified with InnoTyper 21 using an earlier version of the kit that employed a different size standard (CC5 from Promega), used a maximum DNA input volume of $10 \mu \mathrm{L}$, and did not include an allelic ladder for fragment sizing. For the sensitivity study, three sets of human remains were diluted to eight different concentrations of each sample (500 pg, $250 \mathrm{pg}, 125 \mathrm{pg}, 62.5 \mathrm{pg}, 31.25 \mathrm{pg}, 15.63 \mathrm{pg}, 7.8 \mathrm{pg}, 3.9$ pg) and amplified with InnoTyper 21. Additionally, a set of 16 human remains, including bone and teeth, that previously produced no or very partial profiles using STR and mtDNA were amplified with InnoTyper 21. The samples were injected on a 3130xl Genetic Analyzer with POP- $6^{\mathrm{TM}}$ polymer (Applied Biosystems) and analyzed using a 50 or $100 \mathrm{RFU}$ analytical threshold.

\section{Population Database Study}

A total of 592 samples obtained under an IRB exemption for discarded, anonymous samples from five sample populations (African-American, $n=207$; Hispanic, $n=40$; US Caucasian, $n=205$; United Kingdom Caucasians, $n=96$, and Asian, $n=44$ ) were typed for the InnoTyper loci. Population and statistical analyses, including $\mathrm{F}_{\mathrm{ST}}$, for the INNUL markers amplified by the InnoTyper 21 kit were performed for major population groups with either Genetic Data Analysis (GDA) software [44] or in-house developed software. Departures from Hardy-Weinberg equilibrium (HWE) and linkage equilibrium were tested using Fisher's exact test. Bonferroni's correction for multiple comparisons was performed according to Weir and Cockerham [45]. 


\section{Results and Discussion}

\section{Accuracy, Precision, and Reproducibility}

Accuracy is the degree to which the result of a measurement conforms to its actual value. Precision characterizes the degree of mutual agreement among a series of individual measurements, values and/or results. Precision depends only on the distribution of random errors and does not relate to the true value or specified value. Sizing accuracy and precision of the InnoTyper 21 system were assessed first with measurements of the allelic ladder from six injections run on the Applied Biosystems ${ }^{\circledR} 3130$ Genetic Analyzer with POP- $4{ }^{\mathrm{TM}}$ polymer. Supplemental Table 1 shows the mean size of each allele and its SD, which was shown to be less than $0.05 \mathrm{bp}$ for every allele, demonstrating highly precise sizing for every allele in the InnoTyper 21 kit. Accuracy also was assessed with seventy-five amplified samples (twenty-five DNA samples amplified in triplicate) to measure the deviation of each sample allele from the corresponding allelic ladder allele. The InnoTyper 21 Allelic Ladder was loaded once for every fifteen samples (4 injections per an allelic ladder). Supplemental Table 2 shows the sizing precision results obtained from multiple runs of the sample alleles analyzed with the Local Southern sizing method. The total of 2301 sample alleles were separated into each InnoTyper 21 allele and analyzed to evaluate various sizing parameters (maximum, minimum, range, mean, and SD). Across all sizing methods used (Local Southern, $2^{\text {nd }}$ order, or $3^{\text {rd }}$ order least squares), the largest range observed was ACA1766-N, which was $0.32 \mathrm{bp}(\mathrm{n}=51)$. With the Local Southern sizing method, four alleles exceeded 0.2 bp: MLS26-N (0.29 bp, n=66), ALU79712-I (0.23 bp, n=45), ACA1766-N (0.32 bp, n=51, and SB19.12-I (0.26 bp, n=39). With the $2^{\text {nd }}$ order sizing method, the same four alleles exceeded $0.2 \mathrm{bp}$ : MLS26-N (0.3 bp, n=66), ALU79712-I (0.25 bp, n=45), ACA1766-N (0.32 bp, n=51, and SB19.12-I (0.21 bp, n=39). With the $3^{\text {rd }}$ order sizing method, seven alleles exceeded $0.2 \mathrm{bp}$ (data not shown). Therefore, the Local Southern 
and $2^{\text {nd }}$ order sizing methods were more precise, and both exceeded the precision observed with the $3^{\text {rd }}$ order sizing method. The rest of the sample alleles showed ranges less than $0.2 \mathrm{bp}$. Figure 3 shows the size differences observed between the sample alleles and the mean of the allelic ladder alleles on the Applied Biosystems 3130 Genetic Analyzer with POP- $4^{\mathrm{TM}}$ polymer, analyzed with the Local Southern and 2nd order sizing methods. The deviations of the sample allele sizes from the allelic ladder sizes, regardless of which sizing method was used, were all less than $\pm 0.3 \mathrm{bp}$, showing highly accurate sizing results for each allele. All sizing methods tested produced $100 \%$ concordance and generated acceptable data. The genotypes of each DNA sample amplified in triplicate produced the same profile, showing the reproducibility of this system. 

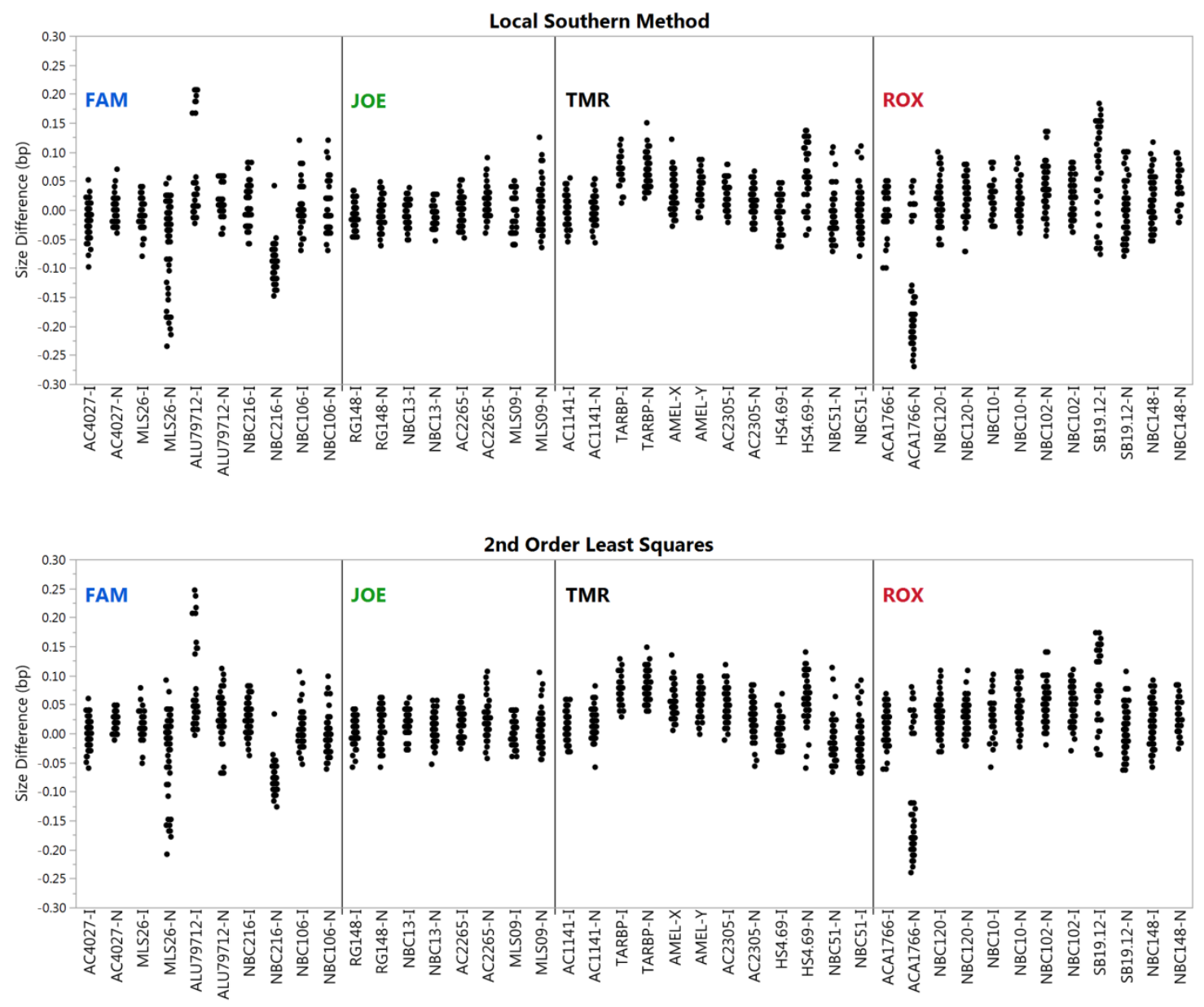

Figure 3. Accuracy shown by size deviation and fluorophore of 2301 sample alleles from the allelic ladder alleles run on the Applied Biosystems ${ }^{\circledR} 3130$ Genetic Analyzer and analyzed with the Local Southern and $2^{\text {nd }}$ order sizing methods.

While the accuracy and precision results are quite impressive and similar to those obtained for STR typing results, such high quality results are not necessarily required for INNUL alleles.

Unlike STRs, INNULs have only two alleles and have amplicon allele size differences > 2 bases.

Therefore, the precision and accuracy of the system exceeds the requirements for correct allele calls.

\section{Species Specificity}

Primers in the InnoTyper 21 kit have been designed to amplify human genomic DNA targeting young Alu elements. A variety of animal and microbial DNA samples were tested to 
assess the human specificity of the kit's performance. At lower DNA input (5 ng) no allelic artifacts were observed in the non-primate species DNA. At higher amounts of non-primate species DNA (10 ng) some non-allelic artifacts were observed in the electropherograms listed in Table 2. Only one reproducible low level allelic peak (<100 RFU) was observed with chicken DNA when $10 \mathrm{ng}$ input DNA was amplified (Table 2). On the other hand, of the primate DNA samples, chimpanzee and to a lesser extent orangutan and green monkey yielded partial profiles (Table 2). DNA from chimpanzee produced an interesting profile with homozygous peaks at every locus with InnoTyper 21. This result was expected due to genomic similarity among higher primates, especially those closest to humans. Interestingly, none of the peaks produced from the non-human primate species, chimpanzee or orangutan, were insertion alleles. Figure 4 shows the electropherogram of the InnoTyper 21 profile obtained from the chimpanzee sample. As observed in Figure 4, all peaks detected were no-insertion (N) peaks. Some of the peak heights were low, likely due to some sequence variation at the primer binding site. This observation supports the hypothesis that the young Alu elements are evolutionary insertions in the human genome, and therefore only the ancestral genomic state (no insertion peak) is present in higher primates [38].

Table 2. Cross reactivity of InnoTyper 21 on DNA extracts from various organisms.

\begin{tabular}{|c|c|c|c|c|c|c|c|}
\hline \multirow[t]{2}{*}{ Species } & \multirow{2}{*}{$\begin{array}{c}\text { DNA } \\
\text { input } \\
\text { (ng) }\end{array}$} & \multicolumn{2}{|r|}{ Reproduced allelic peaks above 100 RFU } & \multicolumn{4}{|c|}{ Reproduced non-allelic or allelic peaks above 50 RFU } \\
\hline & & $\begin{array}{l}\text { Number } \\
\text { of peaks }\end{array}$ & Allele calls & Fluorophore & $\begin{array}{l}\text { Average } \\
\text { size (bp) }\end{array}$ & Allele calls & $\begin{array}{l}\text { Average peak } \\
\text { height (RFU) }\end{array}$ \\
\hline Human & 0.5 & 33 & $\begin{array}{c}\text { AC4027-I, MLS26-IN, ALU79712-N, NBC216-I, } \\
\text { NBC106-IN, RG148-IN, NBC13-N, AC2265-IN, } \\
\text { MLS09-IN, AC1141-I, TARBP-IN, AMEL-XY, } \\
\text { AC2305-IN, HS4.69-IN, NBC51-N, ACA1766- } \\
\text { IN, NBC120-IN, NBC10-N, NBC102-N, } \\
\text { SB19.12-IN, NBC148-I }\end{array}$ & - & - & - & - \\
\hline
\end{tabular}




\begin{tabular}{|c|c|c|c|c|c|c|c|}
\hline Chimpanzee & 1 & 20 & $\begin{array}{l}\text { MLS26-N, ALU79712-N, NBC216-N, NBC106- } \\
\text { N, RG148-N, NBC13-N, AC2265-N, MLS09-N, } \\
\text { AC1141-N, TARBP-N, AMEL-X, AC2305-N, } \\
\text { HS4.69-N, NBC51-N, ACA1766-N, NBC120-N, } \\
\text { NBC10-N, NBC102-N, SB19.12-N, NBC148-N }\end{array}$ & FAM & 68.6 & AC4027-N & 83 \\
\hline Orangutan & 1 & 15 & $\begin{array}{l}\text { AC4027-N, MLS26-N, RG148-N, NBC13-N, } \\
\text { AC2265-N, MLS09-N, AMEL-X, AC2305-N, } \\
\text { HS4.69-N, NBC51-N, ACA1766-N, NBC120-N, } \\
\text { NBC10-N, NBC102-N, NBC148-N }\end{array}$ & FAM & 117.92 & NBC106-OL & 2749 \\
\hline Green monkey & 1 & 7 & $\begin{array}{l}\text { NBC216-N, AC1141-N, AMEL-X, HS4.69-N, } \\
\text { NBC51-N, NBC10-N, NBC102-N }\end{array}$ & - & - & - & - \\
\hline \multirow[t]{2}{*}{ Deer } & 5 & 0 & - & - & - & - & - \\
\hline & 10 & 0 & - & - & - & - & - \\
\hline \multirow[t]{3}{*}{ Dog } & 5 & 0 & - & - & - & - & - \\
\hline & \multirow{2}{*}{10} & \multirow{2}{*}{0} & \multirow{2}{*}{ - } & TMR & 115.12 & OMR & 109 \\
\hline & & & & ROX & 115.2 & OMR & 90 \\
\hline \multirow[t]{2}{*}{ Cat } & 5 & 0 & - & - & - & - & - \\
\hline & 10 & 0 & - & FAM & 112.68 & OMR & 92.5 \\
\hline \multirow[t]{2}{*}{ Rat } & 5 & 0 & - & - & - & - & - \\
\hline & 10 & 0 & - & - & - & - & - \\
\hline \multirow[t]{4}{*}{ Mouse } & 5 & 0 & - & - & - & - & - \\
\hline & \multirow{3}{*}{10} & \multirow{3}{*}{0} & \multirow{3}{*}{-} & FAM & 78.17 & OMR & 96.5 \\
\hline & & & & FAM & 80.76 & MLS26-OL & 65.5 \\
\hline & & & & FAM & 103.98 & NBC216-OL & 527 \\
\hline \multirow[t]{3}{*}{ Chicken } & 5 & 0 & - & - & - & - & - \\
\hline & \multirow{2}{*}{10} & \multirow{2}{*}{0} & \multirow{2}{*}{-} & FAM & 88.4 & OMR & 85 \\
\hline & & & & ROX & 113.39 & SB19.12-N & 66.5 \\
\hline \multirow[t]{2}{*}{ Fish } & 5 & 0 & - & - & - & - & - \\
\hline & 10 & 0 & - & TMR & 83.4 & OMR & 84 \\
\hline \multirow[t]{2}{*}{ Mosquito } & 5 & 0 & - & - & - & - & - \\
\hline & 10 & 0 & - & - & - & - & - \\
\hline \multirow[t]{2}{*}{ S. cerevisiae } & 5 & 0 & - & - & - & - & - \\
\hline & 10 & 0 & - & - & - & - & - \\
\hline S. aureus & 5 & 0 & - & - & - & - & - \\
\hline E. coli & 5 & 0 & - & - & - & - & - \\
\hline R. eutropha & 10 & 0 & - & - & - & - & - \\
\hline R. rubber & 10 & 0 & - & - & - & - & - \\
\hline
\end{tabular}



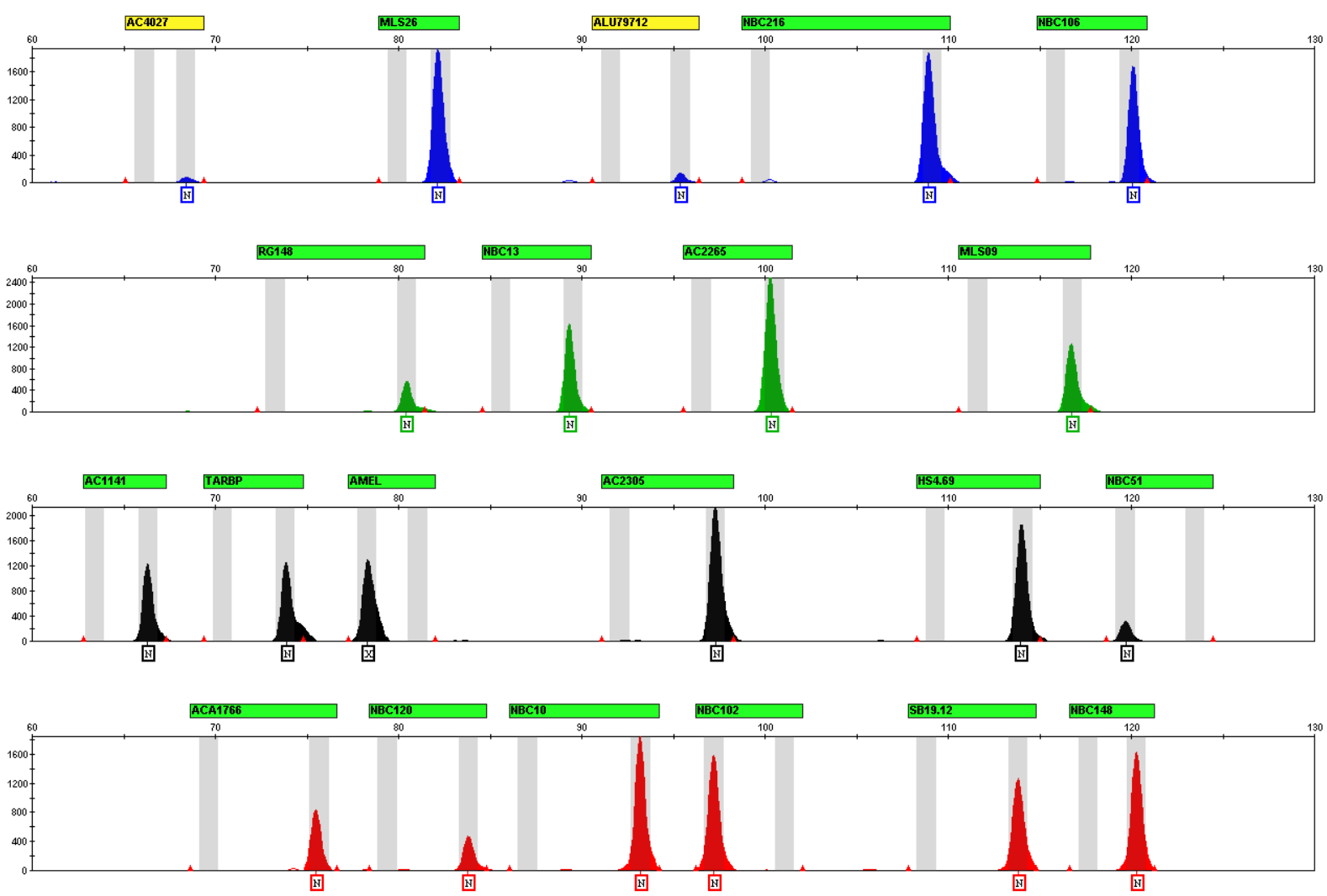

Figure 4. Representative electropherogram of chimpanzee DNA amplified at $1 \mathrm{ng}$. All peaks produced were noinsertion alleles.

\section{Sensitivity Study}

To determine the range of DNA quantities able to produce reliable results and to establish the system's limit of detection, sensitivity studies were performed with pristine samples. Triplicate results of the two serially diluted genomic DNA samples are summarized in Table 3 for mean profile recovery (\%), mean peak height (RFU), and mean PHR. Full profiles were recovered with as low as $100 \mathrm{pg}$ template input for both DNA samples. The input amounts less than 100 pg exhibited drop-out alleles resulting in partial profile recoveries. Over $93 \%$ of the profiles were recovered at $50 \mathrm{pg}$ input DNA for both DNA samples. No drop-in alleles were observed across the tested range of input DNA. The PHR at 400 pg DNA input exhibited relatively well balanced heterozygous peaks. PHR decreased as the amount of input DNA 
decreased, as expected; however, for the heterozygous markers where both alleles were detected above analytical threshold, PHRs were above 0.6 down to $12.5 \mathrm{pg}$ of input DNA. In those markers exhibiting allele dropout, the highest peak height of the surviving sister allele was 226 RFU. Figure 5 shows representative electropherograms of the amplified NIST SRM 2372 Component A samples at the indicated amounts. Reliable DNA profiles were obtained across the range of input DNA tested. Sample quantities above $400 \mathrm{pg}$ of input DNA (data not shown) begin to exhibit the effects of excess template DNA, such as PCR artifacts being formed as well as electrophoresis related artifacts, such as pull up.

Table 3. Effects of varying input DNA on profile recovery, peak height, and peak height ratio.

\begin{tabular}{cccccc}
\hline \multirow{2}{*}{$\begin{array}{c}\text { DNA } \\
\text { Input }(\mathbf{p g})\end{array}$} & \multicolumn{2}{c}{ Mean Profile Recovery (\%) } & \multicolumn{2}{c}{ Mean Peak Height (RFU) } & Mean Peak \\
\cline { 2 - 5 } Height Ratio \\
\hline 400 & $100.0 \pm 0.0$ & $100.0 \pm 0.0$ & $1381 \pm 95$ & $1112 \pm 216$ & $0.84 \pm 0.11$ \\
200 & $100.0 \pm 0.0$ & $100.0 \pm 0.0$ & $738 \pm 40$ & $601 \pm 47$ & $0.77 \pm 0.14$ \\
100 & $100.0 \pm 0.0$ & $100.0 \pm 0.0$ & $381 \pm 34$ & $301 \pm 59$ & $0.66 \pm 0.16$ \\
50 & $95.2 \pm 2.3$ & $93.7 \pm 1.4$ & $183 \pm 20$ & $155 \pm 13$ & $0.67 \pm 0.19$ \\
25 & $79.4 \pm 9.9$ & $71.4 \pm 10.4$ & $107 \pm 12$ & $106 \pm 4$ & $0.68 \pm 0.20$ \\
12.5 & $40.5 \pm 10.4$ & $48.4 \pm 9.9$ & $81 \pm 4$ & $85 \pm 1$ & $0.62 \pm 0.11$ \\
6.25 & $11.9 \pm 4.1$ & $20.6 \pm 5.5$ & $63 \pm 11$ & $66 \pm 8$ & N/A \\
\hline
\end{tabular}




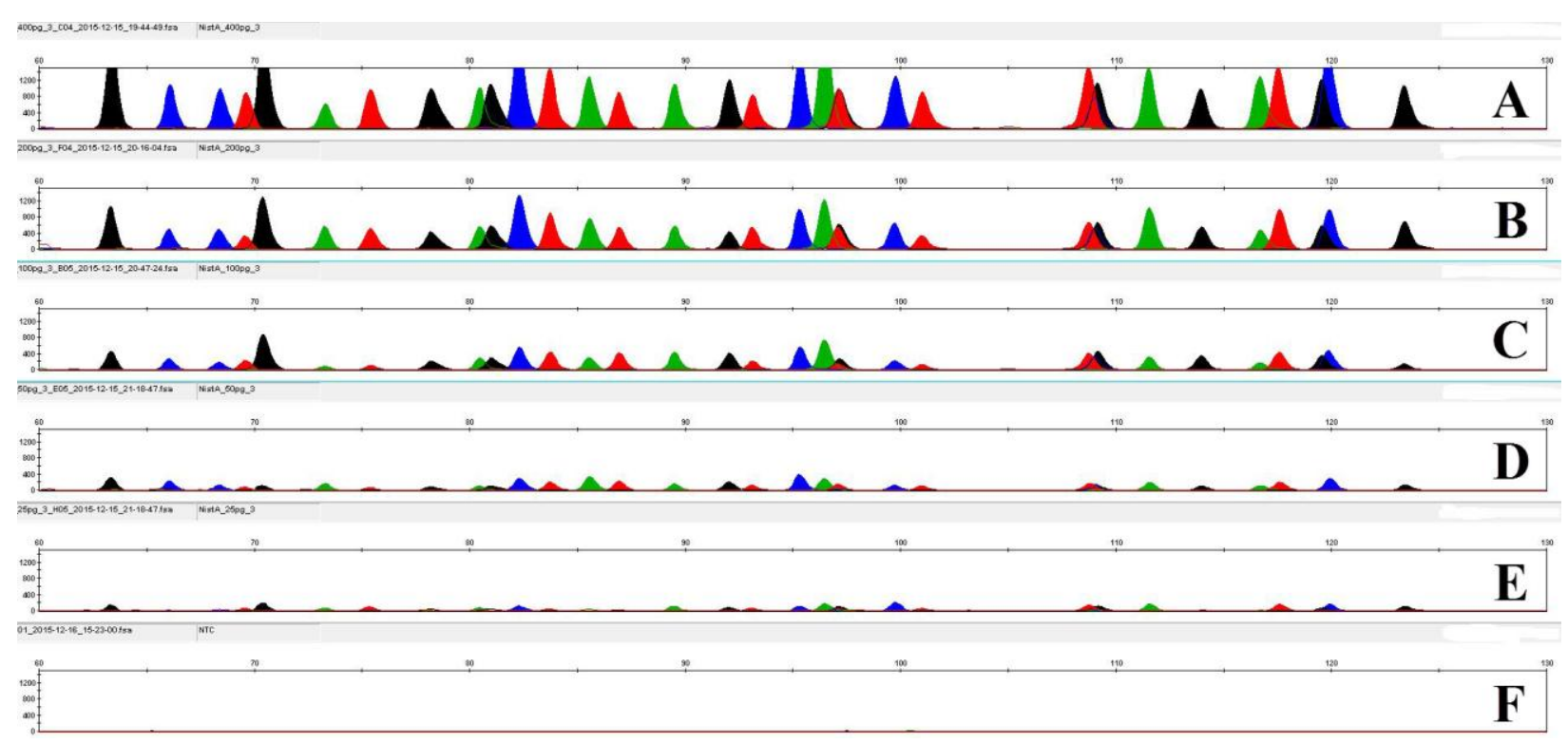

Figure 5. Representative electropherograms from the sensitivity study using NIST SRM 2372 Component A. Panel A, B, C, D, and E show the peak heights of $400 \mathrm{pg}, 200 \mathrm{pg}, 100 \mathrm{pg}, 50 \mathrm{pg}$, and 25pg input DNA, respectively. Panel F shows the electropherogram of the non-template control. The Y-axis scale is set to $1500 \mathrm{RFU}$.

\section{Degradation Study}

Amplicon sizes of widely accepted STR markers can be greater than $200 \mathrm{bp}$ and alleles have been reported to be as long as $500 \mathrm{bp}$ [9], making these large size markers less suitable for analysis of highly degraded DNA samples. However, the largest amplicon in InnoTyper 21 is 123 bp (NBC51 insertion allele). In this study, performance levels of InnoTyper 21, Identifiler Plus [7], and MiniFiler [8] were compared for analyzing degraded DNA samples. Nine different levels of degraded genomic DNA ranging from a DI 0.89 to 241.69 were amplified in triplicate at 200 pg template input DNA (based on the "short" quantitation value from InnoQuant ${ }^{\circledR}$ ), and the profile recoveries and peak heights were assessed (Table 4). InnoTyper 21 was able to recover over $95 \%$ of the profile up to a DI of 75.16, which was 1.4 and $~ 6.6$ times higher than what could be achieved with MiniFiler and Identifiler Plus, respectively (Tables 4 through 7).

Table 4. Effects of degradation on profile recoveries and peak heights of InnoTyper 21, MiniFiler, and Identifiler Plus.

\begin{tabular}{|c|c|c|c|c|c|c|c|}
\hline \multirow[b]{2}{*}{ DI } & \multicolumn{3}{|c|}{ Mean Profile Recovery (\%) } & \multirow[b]{2}{*}{ DI } & \multicolumn{3}{|c|}{ Mean Peak Height (RFU) } \\
\hline & InnoTyper 21 & MiniFiler & Identifiler Plus & & InnoTyper 21 & MiniFiler & Identifiler Plus \\
\hline
\end{tabular}




\begin{tabular}{cccccccc}
0.89 & $100.0 \pm 0.0$ & $100.0 \pm 0.0$ & $100.0 \pm 0.0$ & 0.89 & $596 \pm 20$ & $963 \pm 91$ & $530 \pm 17$ \\
2.16 & $100.0 \pm 0.0$ & $100.0 \pm 0.0$ & $64.6 \pm 4.8$ & 2.16 & $346 \pm 78$ & $397 \pm 58$ & $185 \pm 6$ \\
2.48 & $100.0 \pm 0.0$ & $100.0 \pm 0.0$ & $62.5 \pm 0.0$ & 2.48 & $360 \pm 46$ & $336 \pm 62$ & $181 \pm 19$ \\
13.14 & $99.2 \pm 1.4$ & $83.1 \pm 5.9$ & $39.6 \pm 1.8$ & 13.14 & $312 \pm 34$ & $236 \pm 18$ & $137 \pm 48$ \\
15.16 & $99.2 \pm 1.4$ & $87.0 \pm 6.4$ & $33.3 \pm 3.6$ & 15.16 & $335 \pm 53$ & $249 \pm 18$ & $122 \pm 21$ \\
62.42 & $96.8 \pm 1.4$ & $72.2 \pm 0.0$ & $13.5 \pm 1.8$ & 62.42 & $298 \pm 16$ & $218 \pm 16$ & $111 \pm 14$ \\
66.16 & $98.4 \pm 2.7$ & $75.9 \pm 3.2$ & $16.7 \pm 3.6$ & 66.16 & $269 \pm 33$ & $234 \pm 34$ & $102 \pm 15$ \\
75.16 & $96.0 \pm 3.6$ & $70.4 \pm 3.2$ & $14.6 \pm 4.8$ & 75.16 & $317 \pm 27$ & $222 \pm 13$ & $120 \pm 24$ \\
241.69 & $81 \pm 7.2$ & $63.0 \pm 3.2$ & $4.2 \pm 3.6$ & 241.69 & $249 \pm 5$ & $148 \pm 11$ & $80 \pm 75$ \\
\hline
\end{tabular}

Table 5. Heat map of InnoTyper 21 degradation study results. Alleles are listed by size from the smallest to the largest base pair size. The table indicates the number of replicates (out of three replicate amplifications of each sample) exhibiting allele dropout for a particular allele. Green cells indicate no dropout was observed; red cells indicate the number of replicates where dropout was observed.

\begin{tabular}{|c|c|c|c|c|c|c|c|c|c|c|c|}
\hline \multirow{2}{*}{ Marker } & \multirow{2}{*}{ Allele } & \multirow{2}{*}{$\begin{array}{c}\text { Allele } \\
\text { Size (bp) }\end{array}$} & \multicolumn{9}{|c|}{ Degradation Index } \\
\hline & & & 0.89 & 2.16 & 2.48 & 13.14 & 15.16 & 62.42 & 66.16 & 75.16 & 241.69 \\
\hline AC1141 & I & 63.25 & & & & & & & & & \\
\hline AC1141 & $\mathrm{N}$ & 66.11 & & & & & & & & & \\
\hline AC4027 & I & 66.18 & & & & & & & & & \\
\hline AC4027 & $\mathrm{N}$ & 68.57 & & & & & & & & & \\
\hline ACA1766 & I & 69.32 & & & & & & & & & \\
\hline TARBP & I & 70.24 & & & & & & & & & \\
\hline RG148 & I & 73.38 & & & & & & & & & \\
\hline ACA1766 & $\mathrm{N}$ & 75.11 & & & & & & & & & \\
\hline AMEL & $\mathrm{X}$ & 77.95 & & & & & & & & & \\
\hline $\mathrm{NBC} 120$ & I & 78.98 & & & & & & & & & \\
\hline MLS26 & I & 79.92 & & & & & & & & & \\
\hline RG148 & $\mathrm{N}$ & 80.64 & & & & & & & & & \\
\hline MLS26 & $\mathrm{N}$ & 82.38 & & & & & & & & & \\
\hline $\mathrm{NBC} 13$ & I & 85.45 & & & & & & & & & \\
\hline NBC13 & $\mathrm{N}$ & 89.48 & & & & & & & & & \\
\hline NBC10 & $\mathrm{N}$ & 92.87 & & & & & & & & & \\
\hline ALU79712 & $\mathrm{N}$ & 95.48 & & & & & & & & & \\
\hline AC2265 & I & 96.46 & & & & & & & & 1 & \\
\hline NBC102 & $\mathrm{N}$ & 96.86 & & & & & & & & & \\
\hline AC2305 & $\mathrm{N}$ & 97.03 & & & & & & & & & \\
\hline NBC216 & I & 99.81 & & & & & & & & & \\
\hline AC2265 & $\mathrm{N}$ & 100.56 & & & & & & & & & 1 \\
\hline SB19.12 & I & 108.33 & & & & & & & & & 2 \\
\hline HS4.69 & I & 108.83 & & & & & & & & & 1 \\
\hline SB19.12 & $\mathrm{N}$ & 113.25 & & & & & & & & & 2 \\
\hline HS4.69 & $\mathrm{N}$ & 113.67 & & & & & & & & & 1 \\
\hline NBC106 & I & 115.91 & & & & & & & 1 & & 2 \\
\hline MLS09 & $\mathrm{N}$ & 116.73 & & & & & & & & & 1 \\
\hline NBC148 & I & 117.23 & & & & & & & & 1 & 3 \\
\hline NBC51 & $\mathrm{N}$ & 119.46 & & & & & & & & & 2 \\
\hline NBC106 & $\mathrm{N}$ & 119.95 & & & & & & 3 & 1 & 1 & 3 \\
\hline NBC148 & $\mathrm{N}$ & 119.95 & & & & 1 & 1 & 1 & & 2 & 3 \\
\hline
\end{tabular}

Table 6. Heat map of MiniFiler degradation study results. Alleles are listed by size from the smallest to the largest base pair size. The table indicates the number of replicates (out of three replicate amplifications of each sample) exhibiting allele dropout for a particular allele. Green cells indicate no dropout was observed; red cells indicate the number of replicates where dropout was observed.

\begin{tabular}{ccc|ccccccccc}
\multirow{2}{*}{ Marker } & \multirow{2}{*}{ Allele } & Allele & \multicolumn{1}{c}{ Degradation Index } \\
& & Size (bp) & $\mathbf{0 . 8 9}$ & $\mathbf{2 . 1 6}$ & $\mathbf{2 . 4 8}$ & $\mathbf{1 3 . 1 4}$ & $\mathbf{1 5 . 1 6}$ & $\mathbf{6 2 . 4 2}$ & $\mathbf{6 6 . 1 6}$ & $\mathbf{7 5 . 1 6}$ & $\mathbf{2 4 1 . 6 9}$ \\
\hline D16S539 & 11 & 98.66 & & & & &
\end{tabular}




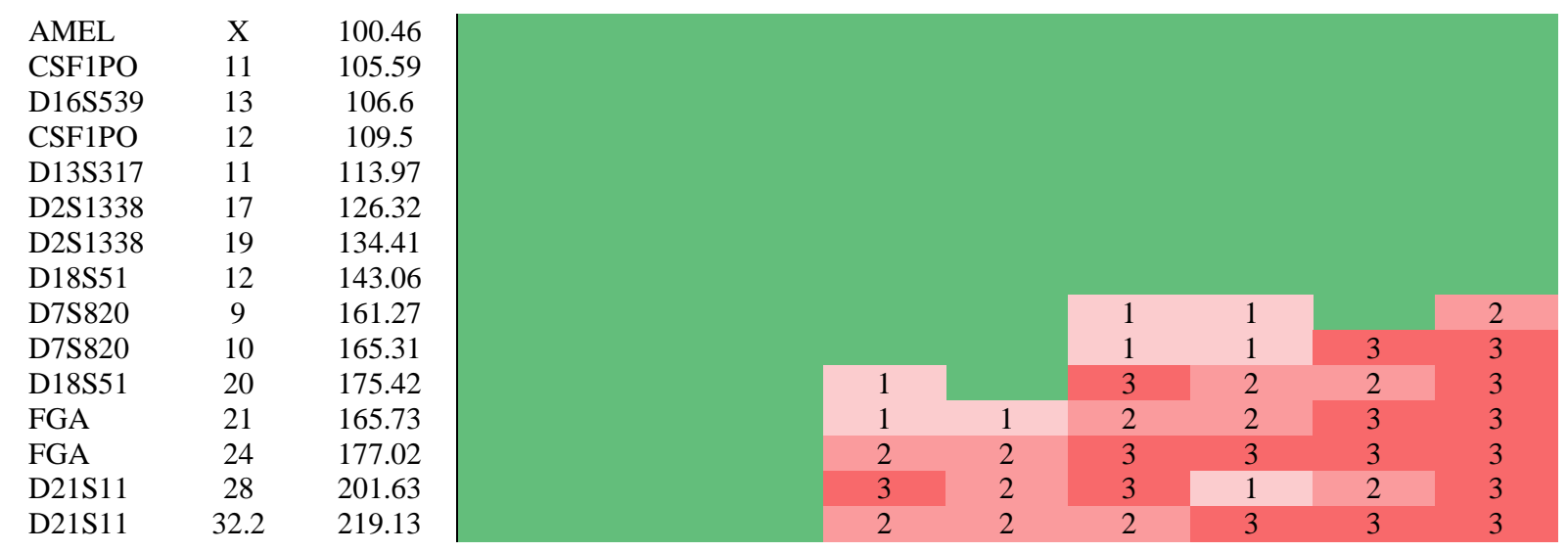

Table 7. Heat map of Identifiler Plus degradation study results. Alleles are listed by size from the smallest to the largest base pair size. The table indicates the number of replicates (out of three replicate amplifications of each sample) exhibiting allele dropout for a particular allele. Green cells indicate no dropout was observed; red cells indicate the number of replicates where dropout was observed.

\begin{tabular}{|c|c|c|c|c|c|c|c|c|c|c|c|}
\hline \multirow{2}{*}{ Marker } & \multirow{2}{*}{ Allele } & \multirow{2}{*}{$\begin{array}{c}\text { Allele } \\
\text { Size (bp) }\end{array}$} & \multicolumn{9}{|c|}{ Degradation Index } \\
\hline & & & 0.89 & 2.16 & 2.48 & 13.14 & 15.16 & 62.42 & 66.16 & 75.16 & 241.69 \\
\hline AMEL & $\mathrm{X}$ & 105.67 & & & & & & & & & 1 \\
\hline D19S433 & 13 & 116.79 & & & & & & 1 & 3 & 3 & 3 \\
\hline D3S1358 & 14 & 118.87 & & & & & & 1 & & & 3 \\
\hline D3S1358 & 15 & 122.84 & & & & & & 1 & 2 & 1 & 3 \\
\hline D19S433 & 15 & 124.89 & & & & & 1 & 3 & 2 & 3 & 3 \\
\hline D8S1179 & 10 & 130.22 & & & & & & 3 & 1 & 1 & 3 \\
\hline D8S1179 & 14 & 147.45 & & & & 2 & 1 & 2 & 2 & 2 & 3 \\
\hline D5S818 & 11 & 150.68 & & & & & & 3 & 2 & 3 & 3 \\
\hline vWA & 16 & 173.99 & & & 1 & 1 & 3 & 3 & 3 & 3 & 3 \\
\hline vWA & 18 & 182.07 & & & 2 & 3 & 3 & 3 & 3 & 3 & 3 \\
\hline TH01 & 9.3 & 185.5 & & & & & 1 & 3 & 3 & 3 & 3 \\
\hline D21S11 & 28 & 199.76 & & & 1 & 3 & 3 & 3 & 3 & 3 & 3 \\
\hline D21S11 & 32.2 & 217.71 & & 2 & 2 & 3 & 3 & 3 & 3 & 3 & 3 \\
\hline D13S317 & 11 & 227.94 & & & & 3 & 3 & 3 & 3 & 3 & 3 \\
\hline FGA & 21 & 229.72 & & 3 & 2 & 3 & 3 & 3 & 3 & 3 & 3 \\
\hline TPOX & 11 & 241.51 & & & & 2 & 3 & 3 & 3 & 3 & 3 \\
\hline FGA & 24 & 241.85 & & 3 & 2 & 3 & 3 & 3 & 3 & 3 & 3 \\
\hline D7S820 & 9 & 266.64 & & 3 & 3 & 3 & 3 & 3 & 3 & 3 & 3 \\
\hline D7S820 & 10 & 270.67 & & 3 & 3 & 3 & 3 & 3 & 3 & 3 & 3 \\
\hline D16S539 & 11 & 275.78 & & 1 & 2 & 3 & 3 & 3 & 3 & 3 & 3 \\
\hline D18S51 & 12 & 281.7 & & 3 & 3 & 3 & 3 & 3 & 3 & 3 & 3 \\
\hline D16S539 & 13 & 283.83 & & 1 & 1 & 3 & 3 & 3 & 3 & 3 & 3 \\
\hline D2S1338 & 17 & 314.23 & & 3 & 3 & 3 & 3 & 3 & 3 & 3 & 3 \\
\hline D18S51 & 20 & 314.59 & & 3 & 3 & 3 & 3 & 3 & 3 & 3 & 3 \\
\hline D2S1338 & 19 & 322.37 & & 3 & 2 & 3 & 3 & 3 & 3 & 3 & 3 \\
\hline CSF1PO & 11 & 324.11 & & 3 & 3 & 3 & 3 & 3 & 3 & 3 & 3 \\
\hline CSF1PO & 12 & 328.15 & & 3 & 3 & 3 & 3 & 3 & 3 & 3 & 3 \\
\hline
\end{tabular}

Studies were performed on the highest DI sample (241.69) to determine the effect of low concentrations on a highly degraded sample. The DI 241.69 sample was serially diluted and amplified with InnoTyper 21 and MiniFiler at $400 \mathrm{pg}$ to $25 \mathrm{pg}$ of total input DNA. Figure 6 and Supplemental Table 3 show the mean profile recovery and mean peak heights obtained from 
typing the serially diluted highly degraded sample. Supplemental Tables 4 and 5 show drop-out heat maps for the replicate amplifications with InnoTyper 21 and MiniFiler, respectively. These results clearly indicate that although allele dropout is more extensive with both low quantity and quality DNA, the InnoTyper 21 kit recovers a higher percentage of alleles than MiniFiler with these highly compromised samples.
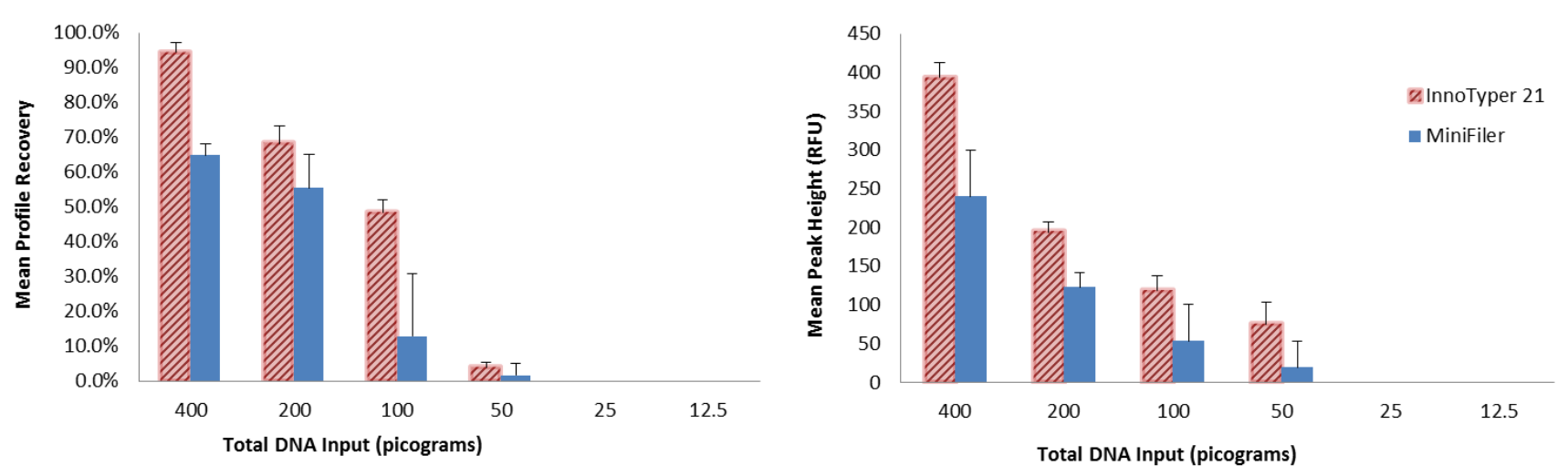

Figure 6. Mean profile recoveries and peak heights (RFU) of InnoTyper 21 and MiniFiler with various quantities of a sample with severely degraded template DNA (Degradation Index of 241.69).

\section{Inhibition Study}

Inhibition studies were performed with hematin, humic acid, and melanin to evaluate performance of the InnoTyper 21 kit in the presence of PCR inhibitors. DNA samples from crime scenes may contain inhibitors that can affect amplification of DNA samples. $400 \mathrm{pg}$ of the kit control DNA was amplified in triplicate in the presence of various concentrations of the inhibitors (Table 8). Complete inhibition was observed as the concentration of hematin reached $75 \mu \mathrm{M}$. With humic acid, a 50\% peak height reduction was observed at a concentration of 30 $\mathrm{ng} / \mu \mathrm{L}$ of humic acid. Melanin up to $10 \mathrm{ng} / \mu \mathrm{L}$ concentration did not produce allele drop-out, but there was slight reduction in peak heights observed with higher melanin concentrations.

Table 8. Amplification efficiency of control DNA 1212 in the presence of increasing amounts of hematin, melanin, and humic acid.

\begin{tabular}{ccc||ccc||ccc}
\hline $\begin{array}{c}\text { Hematin } \\
(\mu \mathrm{M})\end{array}$ & $\begin{array}{c}\text { Mean Profile } \\
\text { Recovery }(\%)\end{array}$ & $\begin{array}{c}\text { Mean Peak } \\
\text { Height }\end{array}$ & $\begin{array}{c}\text { Melanin } \\
(\mathrm{ng} / \mu \mathrm{L})\end{array}$ & $\begin{array}{c}\text { Mean Profile } \\
\text { Recovery }(\%)\end{array}$ & $\begin{array}{c}\text { Mean Peak } \\
\text { Height }\end{array}$ & $\begin{array}{c}\text { Humic Acid } \\
(\mathrm{ng} / \mu \mathrm{L})\end{array}$ & $\begin{array}{c}\text { Mean Profile } \\
\text { Recovery }(\%)\end{array}$ & $\begin{array}{c}\text { Mean Peak } \\
\text { Height }\end{array}$ \\
\hline
\end{tabular}




\begin{tabular}{|c|c|c|c|c|c|c|c|c|}
\hline & & (RFU) & & & (RFU) & & & (RFU) \\
\hline 15 & 100.0 & $1181 \pm 118$ & 1.25 & 100.0 & $1343 \pm 129$ & 5 & 100.0 & $1053 \pm 198$ \\
\hline 30 & 100.0 & $1079 \pm 160$ & 2.5 & 100.0 & $1554 \pm 236$ & 10 & 100.0 & $1066 \pm 147$ \\
\hline 45 & 100.0 & $621 \pm 51$ & 3.75 & 100.0 & $1448 \pm 78$ & 15 & 100.0 & $1033 \pm 167$ \\
\hline 60 & $25.4 \pm 14.6$ & $119 \pm 38$ & 5 & 100.0 & $1382 \pm 232$ & 20 & 100.0 & $599 \pm 70$ \\
\hline 90 & 0.0 & 0 & 7.5 & 100.0 & $1004 \pm 68$ & 30 & $52.4 \pm 14.9$ & $201 \pm 26$ \\
\hline 105 & 0.0 & 0 & 10 & 100.0 & $966 \pm 47$ & & & \\
\hline
\end{tabular}

\section{Mixture Study}

Two pristine female and male genomic DNA samples were mixed at various ratios and analyzed for peak height ratio (PHR). The genotypes of the major and minor contributor DNA, the observed PHRs, and theoretical PHRs are summarized in Supplemental Table 6. The mixtures of a homozygous allele of the major component and heterozygous alleles of the minor component seen in TARBP and AMEL showed a peak height imbalance at all the tested ratios, especially with the low amount of the minor component. This mixing pattern results in a sister allele originating from the heterozygous genotype of the minor DNA. The heterozygous alleles of the minor DNA keeps the PHR less than 0.33 (theoretical PHR) all the way up to the $1: 1$ mixing ratio. The observed PHRs ranged from 0.04 to 0.44 , and the theoretical PHRs range from 0.03 to 0.33 at the tested ratios. Another pattern that produces heterozygous alleles is a mixture of an opposite homozygous allele. The PHR less than 0.33 (theoretical) can be obtained at the ratios, 15:1, 7:1, and 3:1. The 1:1 ratio gives a PHR equal to 1.0. The mixtures of heterozygous alleles of the major donor with a homozygous allele of the minor donor as seen in the markers AC4027, MLS26, NBC106, RG148, NBC13, AC2265, and HS4.69 showed the decrease in PHR as the contribution of the minor donor increases. At the mixture ratio 1:1, the observed PHRs ranged between 0.25 and 0.33 . The ratios other than $1: 1$ have relatively high PHR in both 
observed and theoretical. PHRs of twenty-five single source samples amplified at $500 \mathrm{pg}$ in triplicate were summarized in Supplemental Table 7. The PHR of each marker is relatively high (mean $\geq 0.78$, median $\geq 0.80$ ). The lowest PHR observed was 0.51 in NBC13 and AC1141.

Detection of mixed samples in a bi-allelic system depends solely upon notable differences in peak height, such as would be seen with low PHRs. If both major and minor components exhibit the same homozygous allele or heterozygous alleles, there will be no indicators of the proportions of the contributors. However, mixing of the opposite homozygous alleles or a homozygous allele with heterozygous alleles can result in notable peak imbalance with certain mixture ratios. Based upon the theoretical PHR calculation of the two-source mixture and comparison of PHR of single source DNA with that of the mixture, a PHR $\leq 0.33$ appears to be an appropriate cutoff for interpretation of two source samples. However, detection of mixtures of more than two will be more complicated and is challenging with a bi-allelic system with only 21 markers. In addition, stochastic effects can impact the PHR with low level samples and caution should be exercised when attempting to deconvolve mixtures based on PHR when the quantity of template DNA (total or of a contributor) is low. Overall, the performance of InnoTyper 21 on mixed samples behaved as expected.

\section{Case-Type Samples Study}

The results obtained using InnoTyper 21 were generally consistent with those obtained from other typing systems. The significant exception was for the highly degraded samples, with which InnoTyper 21 had a higher portion of profile recovery. An example of this is nonprobative sample NO1-010, a degraded semen sample with a DI value of 7.41. Identifiler Plus produced a partial profile with allelic dropout observed at six STR loci, and InnoTyper 21 
produced a full profile (Figure 7). This was the general trend observed across the degraded samples tested as part of the non-probative study. All reagent blanks produced no results.

A summary of the non-probative sample results can be found in Supplemental Table 8, which shows the sample description, DI values, total input DNA used for InnoTyper 21 typing, the InnoTyper 21 result, and average peak heights for all the non-probative samples tested. The overall average PHR for the single source case-type samples was 0.92 with a standard deviation of 0.03. Peak heights for the non-probative samples were well-balanced and correlated with the input DNA in the sample. Overall, peak heights were within acceptable ranges. Also, the DI values in conjunction with the total input DNA correlated well with the observed peak heights of the non-probative samples. The non-probative sample study supports the effectiveness of using InnoTyper 21 for typing highly degraded samples.

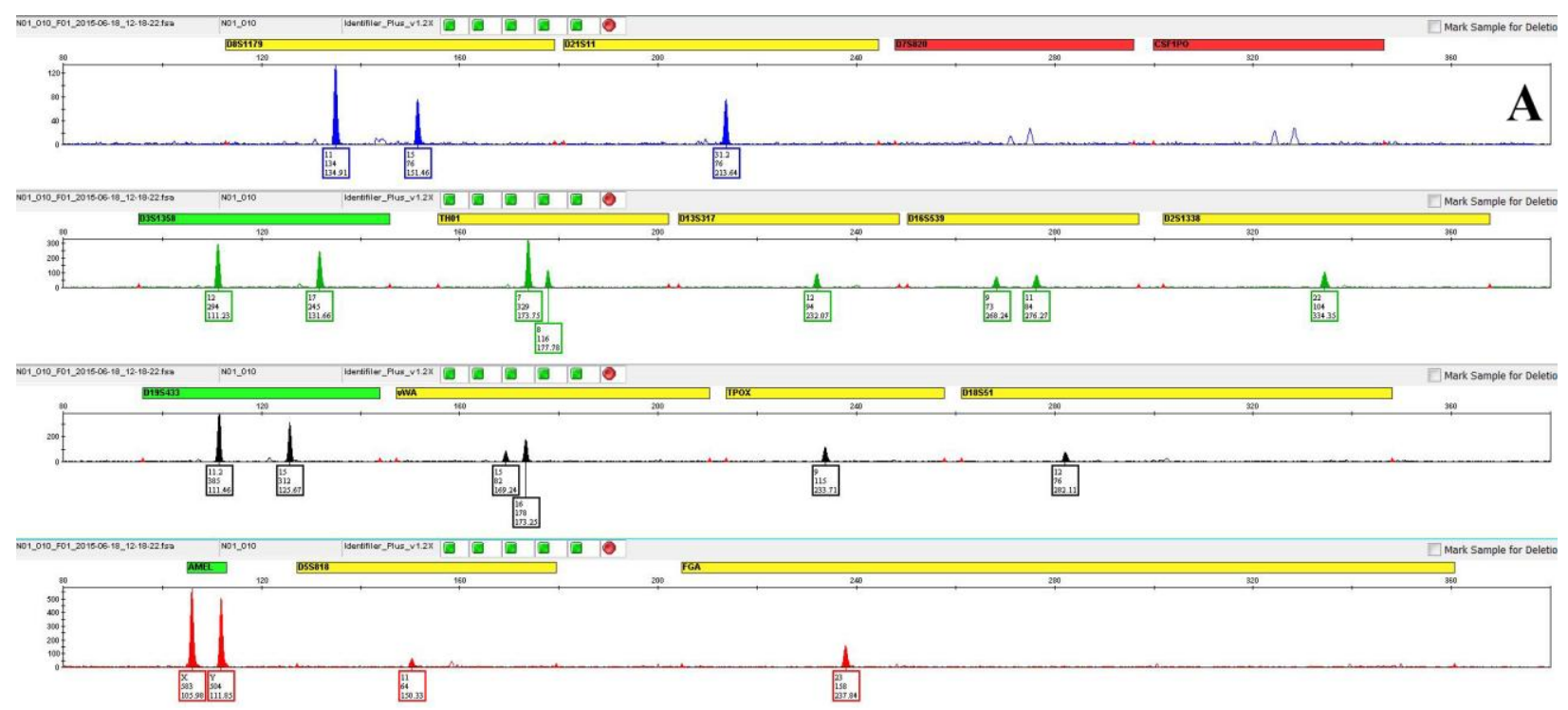




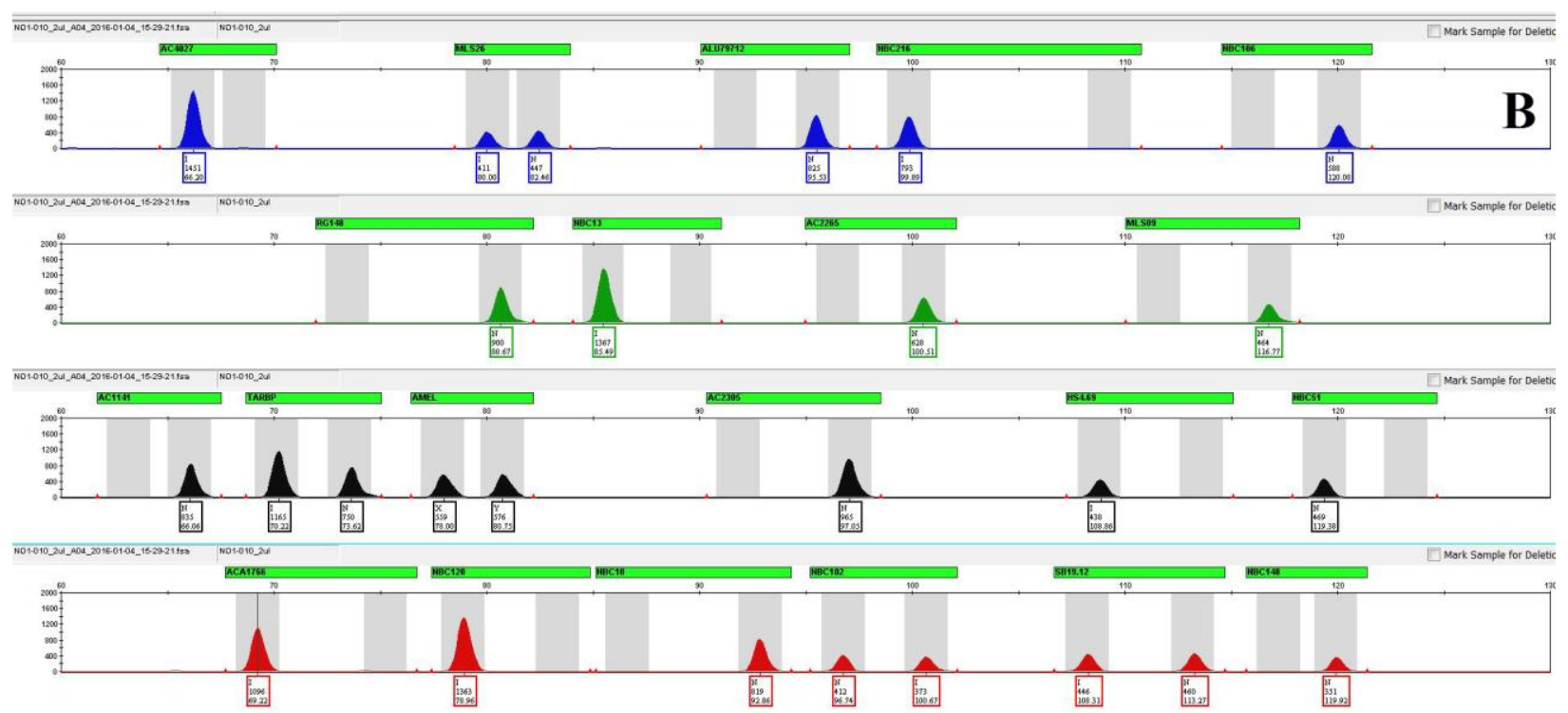

Figure 7. Non-probative degraded semen sample tested with Identifiler Plus (A) and InnoTyper 21 (B).

Of interest, a microvariant allele in marker NBC120 was observed in a blood sample in the non-probative study (Figure 8). This "off-ladder" allele is approximately one base pair smaller in size than the corresponding no insertion ladder allele and was confirmed by multiple amplifications as well as sequencing. The sequencing results verify a single base pair deletion downstream from the forward primer. This type of rare occurrence has been observed in the past with other typing systems and is likely due to variants in or around the primer-binding site [27]. Refer to the microvariant discussion in the Population Database Study for further details. 


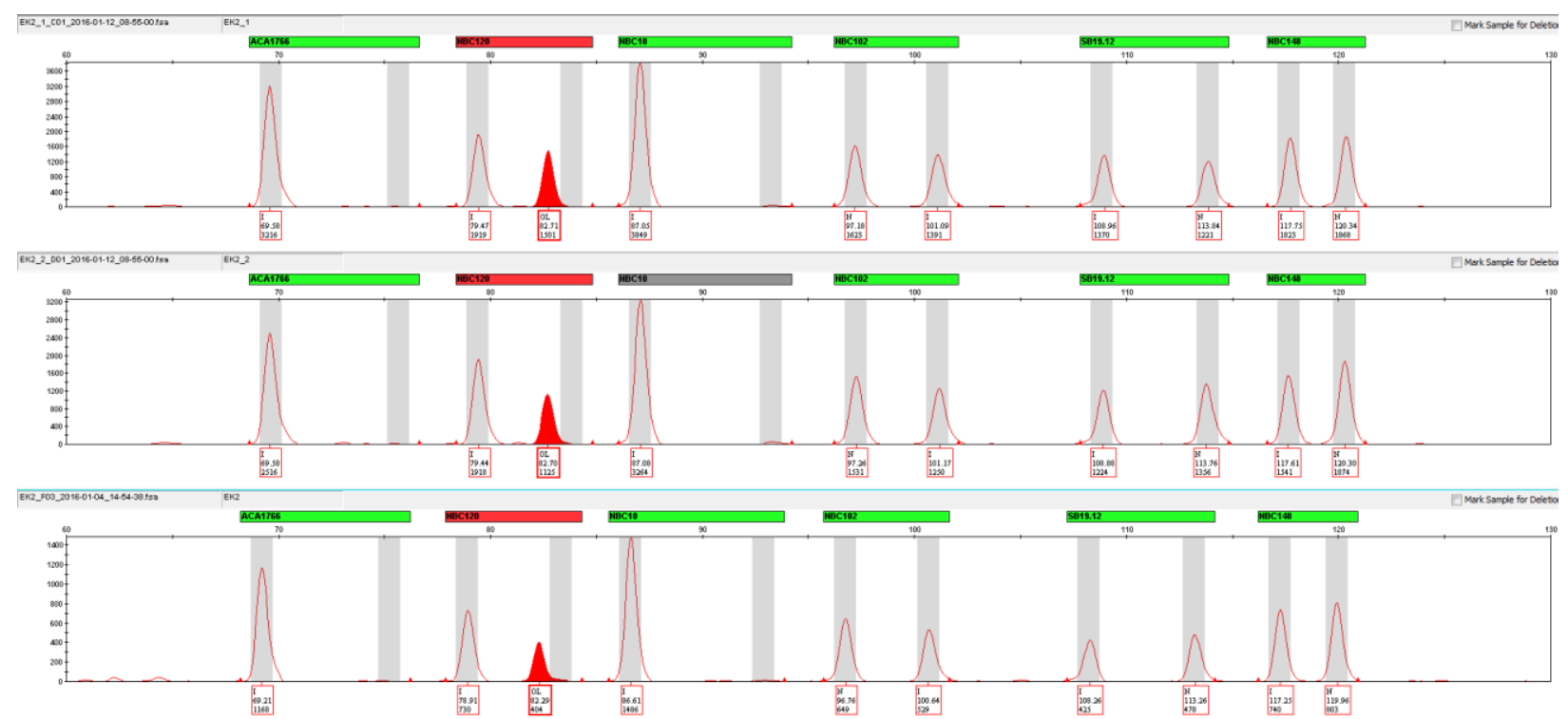

Figure 8. Microvariant allele observed at locus NBC120 in non-probative blood sample amplified three times.

\section{Analysis of highly degraded non-probative human remains}

The results of the sensitivity study performed with human remains shows full, concordant profiles were obtained with as low as $31.25 \mathrm{pg}$ of total input DNA, according to the quantitation values from Quantifiler Duo (Table 9). Below 31.25 pg of total DNA input, stochastic effects such as drop out and artifacts were observed. For example, there was one allele drop-in detected in one marker of one sample at $3.9 \mathrm{pg}$ of total input DNA. Results between $250 \mathrm{pg}$ and $62.5 \mathrm{pg}$ exhibited well balanced profiles with minimal background noise. $500 \mathrm{pg}$ of input DNA resulted in artifacts of excessive template DNA. Results of this study show that sensitivity levels of the InnoTyper 21 kit remain high even when used with highly degraded human remains.

Table 9. Results of the sensitivity study performed with three human remains. Darkened cells indicate complete locus dropout; shaded cells indicate allele dropout with the surviving sister allele RFU indicated.

\begin{tabular}{|c|c|c|c|c|c|c|c|c|c|c|c|c|c|c|c|c|c|c|c|c|c|c|}
\hline Sample & $\begin{array}{l}\text { Total Input } \\
(\mathrm{pg})\end{array}$ & $\begin{array}{c}\mathrm{AC} \\
4027\end{array}$ & MLS26 & $\begin{array}{l}\text { ALU } \\
79712\end{array}$ & NBC216 & NBC106 & RG148 & NBC13 & $\begin{array}{c}\mathrm{AC} \\
2265\end{array}$ & MLS09 & $\begin{array}{c}\mathrm{AC} \\
1141\end{array}$ & TARBP & AMEL & $\begin{array}{c}\mathrm{AC} \\
2305\end{array}$ & HS4.69 & NBC51 & $\begin{array}{l}\text { ACA } \\
1766\end{array}$ & $\mathrm{NBC} 120$ & $\mathrm{NBC} 10$ & $\mathrm{NBC} 102$ & SB19.12 & NBC 148 \\
\hline \multirow{8}{*}{ UNT1 } & 3.9 & & $\mathrm{~N}$ & 300 & I & & $\mathrm{I}, \mathrm{N}$ & $\mathrm{N}$ & $\mathrm{I}, \mathrm{N}$ & $\mathrm{N}$ & $\mathrm{N}$ & I & 66 & & I & $\mathrm{N}$ & & & & & & \\
\hline & 7.81 & $\mathrm{I}, \mathrm{N}$ & $\mathrm{N}$ & $\mathrm{I}, \mathrm{N}$ & I & & & $\mathrm{N}$ & $\mathrm{I}, \mathrm{N}$ & $\mathrm{N}$ & I & I & 112 & & I & $\mathrm{N}$ & & $\mathrm{N}$ & & & 84 & \\
\hline & 15.63 & $\mathrm{I}, \mathrm{N}$ & $\mathrm{N}$ & $\mathrm{I}, \mathrm{N}$ & I & $\mathrm{I}, \mathrm{N}$ & $\mathrm{I}, \mathrm{N}$ & $\mathrm{N}$ & 184 & $\mathrm{~N}$ & I & I & $\mathrm{X}, \mathrm{Y}$ & I & I & $\mathrm{N}$ & I & $\mathrm{N}$ & $\mathrm{N}$ & $\mathrm{N}, \mathrm{I}$ & 69 & I \\
\hline & 31.25 & $\mathrm{I}, \mathrm{N}$ & $\mathrm{N}$ & $\mathrm{I}, \mathrm{N}$ & I & $\mathrm{I}, \mathrm{N}$ & $\mathrm{I}, \mathrm{N}$ & $\mathrm{N}$ & $\mathrm{I}, \mathrm{N}$ & $\mathrm{N}$ & I & I & $\mathrm{X}, \mathrm{Y}$ & I & I & $\mathrm{N}$ & I & $\mathrm{N}$ & $\mathrm{N}$ & $\mathrm{N}, \mathrm{I}$ & $\mathrm{I}, \mathrm{N}$ & I \\
\hline & 62.5 & $\mathrm{I}, \mathrm{N}$ & $\mathrm{N}$ & $\mathrm{I}, \mathrm{N}$ & I & $\mathrm{I}, \mathrm{N}$ & $\mathrm{I}, \mathrm{N}$ & $\mathrm{N}$ & $\mathrm{I}, \mathrm{N}$ & $\mathrm{N}$ & I & I & $\mathrm{X}, \mathrm{Y}$ & I & I & $\mathrm{N}$ & I & $\mathrm{N}$ & $\mathrm{N}$ & $\mathrm{N}, \mathrm{I}$ & $\mathrm{I}, \mathrm{N}$ & I \\
\hline & 125 & $\mathrm{I}, \mathrm{N}$ & $\mathrm{N}$ & $\mathrm{I}, \mathrm{N}$ & I & $\mathrm{I}, \mathrm{N}$ & $\mathrm{I}, \mathrm{N}$ & $\mathrm{N}$ & $\mathrm{I}, \mathrm{N}$ & $\mathrm{N}$ & I & I & $X, Y$ & I & I & $\mathrm{N}$ & I & $\mathrm{N}$ & $\mathrm{N}$ & $\mathrm{N}, \mathrm{I}$ & $\mathrm{I}, \mathrm{N}$ & I \\
\hline & 250 & $\mathrm{I}, \mathrm{N}$ & $\mathrm{N}$ & $\mathrm{I}, \mathrm{N}$ & I & $\mathrm{I}, \mathrm{N}$ & $\mathrm{I}, \mathrm{N}$ & $\mathrm{N}$ & $\mathrm{I}, \mathrm{N}$ & $\mathrm{N}$ & I & I & $\mathrm{X}, \mathrm{Y}$ & I & I & $\mathrm{N}$ & I & $\mathrm{N}$ & $\mathrm{N}$ & $\mathrm{N}, \mathrm{I}$ & $\mathrm{I}, \mathrm{N}$ & I \\
\hline & 500 & $\mathrm{I}, \mathrm{N}$ & $\mathrm{N}$ & $\mathrm{I}, \mathrm{N}$ & I & $\mathrm{I}, \mathrm{N}$ & $\mathrm{I}, \mathrm{N}$ & $\mathrm{N}$ & $\mathrm{I}, \mathrm{N}$ & $\mathrm{N}$ & I & I & $X, Y$ & I & I & $\mathrm{N}$ & I & $\mathrm{N}$ & $\mathrm{N}$ & $\mathrm{N}, \mathrm{I}$ & $\mathrm{I}, \mathrm{N}$ & I \\
\hline UNT6 & 3.9 & $\mathrm{~N}$ & $\mathrm{~N}$ & & 325 & $\mathrm{I}, \mathrm{N}$ & $\mathrm{N}$ & $\mathrm{N}$ & I & $\mathrm{I}, \mathrm{N}$ & I & I & $X$ & 88 & $\mathrm{~N}$ & I & 67 & $\mathrm{~N}$ & $\mathrm{~N}$ & & & I \\
\hline
\end{tabular}




\begin{tabular}{|c|c|c|c|c|c|c|c|c|c|c|c|c|c|c|c|c|c|c|c|c|c|c|}
\hline & 7.81 & $\mathrm{~N}$ & $\mathrm{~N}$ & 148 & $\mathrm{I}, \mathrm{N}$ & $\mathrm{I}, \mathrm{N}$ & $\mathrm{N}$ & $\mathrm{N}$ & I & $\mathrm{I}, \mathrm{N}$ & I & & $X$ & $\mathrm{I}, \mathrm{N}$ & $\mathrm{N}$ & I & & $\mathrm{N}$ & & I & & \\
\hline & 15.63 & $\mathrm{~N}$ & $\mathrm{~N}$ & $\mathrm{I}, \mathrm{N}$ & $\mathrm{I}, \mathrm{N}$ & $\mathrm{I}, \mathrm{N}$ & $\mathrm{N}$ & $\mathrm{N}$ & I & $\mathrm{I}, \mathrm{N}$ & I & I & $\mathrm{X}$ & $\mathrm{I}, \mathrm{N}$ & $\mathrm{N}$ & I & 96 & $\mathrm{~N}$ & $\mathrm{~N}$ & I & 124 & I \\
\hline & 31.25 & $\mathrm{~N}$ & $\mathrm{~N}$ & $\mathrm{I}, \mathrm{N}$ & $\mathrm{I}, \mathrm{N}$ & $\mathrm{I}, \mathrm{N}$ & $\mathrm{N}$ & $\mathrm{N}$ & I & $\mathrm{I}, \mathrm{N}$ & I & I & $\mathrm{X}$ & $\mathrm{I}, \mathrm{N}$ & $\mathrm{N}$ & I & $\mathrm{I}, \mathrm{N}$ & $\mathrm{N}$ & $\mathrm{N}$ & I & $\mathrm{I}, \mathrm{N}$ & I \\
\hline & 62.5 & $\mathrm{~N}$ & $\mathrm{~N}$ & $\mathrm{I}, \mathrm{N}$ & $\mathrm{I}, \mathrm{N}$ & $\mathrm{I}, \mathrm{N}$ & $\mathrm{N}$ & $\mathrm{N}$ & I & $\mathrm{I}, \mathrm{N}$ & I & I & $X$ & $\mathrm{I}, \mathrm{N}$ & $\mathrm{N}$ & I & $\mathrm{I}, \mathrm{N}$ & $\mathrm{N}$ & $\mathrm{N}$ & I & $\mathrm{I}, \mathrm{N}$ & I \\
\hline & 125 & $\mathrm{~N}$ & $\mathrm{~N}$ & $\mathrm{I}, \mathrm{N}$ & $\mathrm{I}, \mathrm{N}$ & $\mathrm{I}, \mathrm{N}$ & $\mathrm{N}$ & $\mathrm{N}$ & I & $\mathrm{I}, \mathrm{N}$ & I & I & $\mathrm{X}$ & $\mathrm{I}, \mathrm{N}$ & $\mathrm{N}$ & I & $\mathrm{I}, \mathrm{N}$ & $\mathrm{N}$ & $\mathrm{N}$ & I & $\mathrm{I}, \mathrm{N}$ & I \\
\hline & 250 & $\mathrm{~N}$ & $\mathrm{~N}$ & $\mathrm{I}, \mathrm{N}$ & $\mathrm{I}, \mathrm{N}$ & $\mathrm{I}, \mathrm{N}$ & $\mathrm{N}$ & $\mathrm{N}$ & I & $\mathrm{I}, \mathrm{N}$ & I & I & $\mathrm{X}$ & $\mathrm{I}, \mathrm{N}$ & $\mathrm{N}$ & I & $\mathrm{I}, \mathrm{N}$ & $\mathrm{N}$ & $\mathrm{N}$ & I & $\mathrm{I}, \mathrm{N}$ & I \\
\hline & 500 & $\mathrm{~N}$ & $\mathrm{~N}$ & $\mathrm{I}, \mathrm{N}$ & $\mathrm{I}, \mathrm{N}$ & $\mathrm{I}, \mathrm{N}$ & $\mathrm{N}$ & $\mathrm{N}$ & I & $\mathrm{I}, \mathrm{N}$ & I & I & $X$ & $\mathrm{I}, \mathrm{N}$ & $\mathrm{N}$ & I & $\mathrm{I}, \mathrm{N}$ & $\mathrm{N}$ & $\mathrm{N}$ & I & $\mathrm{I}, \mathrm{N}$ & I \\
\hline \multirow{8}{*}{ UNT7 } & 3.9 & $\mathrm{~N}$ & I & 187 & & $\mathrm{~N}$ & $\mathrm{~N}$ & 153 & $\mathrm{I}, \mathrm{N}$ & $\mathrm{N}$ & 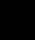 & I & $X, Y$ & & 112 & 96 & 70 & 75 & & & & I \\
\hline & 7.81 & $\mathrm{~N}$ & I & $\mathrm{I}, \mathrm{N}$ & $\mathrm{I}, \mathrm{N}$ & $\mathrm{N}$ & $\mathrm{N}$ & 252 & 352 & $\mathrm{~N}$ & I & I & 237 & $\mathrm{I}, \mathrm{N}$ & 154 & $\mathrm{~N}, \mathrm{I}$ & 73 & 52 & & I & & I \\
\hline & 15.63 & $\mathrm{~N}$ & I & $\mathrm{I}, \mathrm{N}$ & 664 & $\mathrm{~N}$ & $\mathrm{~N}$ & $\mathrm{I}, \mathrm{N}$ & $\mathrm{I}, \mathrm{N}$ & $\mathrm{N}$ & I & I & $X, Y$ & $\mathrm{I}, \mathrm{N}$ & $\mathrm{I}, \mathrm{N}$ & $\mathrm{N}, \mathrm{I}$ & 193 & $\mathrm{I}, \mathrm{N}$ & $\mathrm{I}, \mathrm{N}$ & I & & I \\
\hline & 31.25 & $\mathrm{~N}$ & I & $\mathrm{I}, \mathrm{N}$ & $\mathrm{I}, \mathrm{N}$ & $\mathrm{N}$ & $\mathrm{N}$ & $\mathrm{I}, \mathrm{N}$ & $\mathrm{I}, \mathrm{N}$ & $\mathrm{N}$ & I & I & $\mathrm{X}, \mathrm{Y}$ & $\mathrm{I}, \mathrm{N}$ & $\mathrm{I}, \mathrm{N}$ & $\mathrm{N}, \mathrm{I}$ & $\mathrm{I}, \mathrm{N}$ & $\mathrm{I}, \mathrm{N}$ & $\mathrm{I}, \mathrm{N}$ & I & I & I \\
\hline & 62.5 & $\mathrm{~N}$ & I & $\mathrm{I}, \mathrm{N}$ & $\mathrm{I}, \mathrm{N}$ & $\mathrm{N}$ & $\mathrm{N}$ & $\mathrm{I}, \mathrm{N}$ & $\mathrm{I}, \mathrm{N}$ & $\mathrm{N}$ & I & I & $\mathrm{X}, \mathrm{Y}$ & $\mathrm{I}, \mathrm{N}$ & $\mathrm{I}, \mathrm{N}$ & $\mathrm{N}, \mathrm{I}$ & $\mathrm{I}, \mathrm{N}$ & $\mathrm{I}, \mathrm{N}$ & $\mathrm{I}, \mathrm{N}$ & I & I & I \\
\hline & 125 & $\mathrm{~N}$ & I & $\mathrm{I}, \mathrm{N}$ & $\mathrm{I}, \mathrm{N}$ & $\mathrm{N}$ & $\mathrm{N}$ & $\mathrm{I}, \mathrm{N}$ & $\mathrm{I}, \mathrm{N}$ & $\mathrm{N}$ & I & I & $X, Y$ & $\mathrm{I}, \mathrm{N}$ & $\mathrm{I}, \mathrm{N}$ & $\mathrm{N}, \mathrm{I}$ & $\mathrm{I}, \mathrm{N}$ & $\mathrm{I}, \mathrm{N}$ & $\mathrm{I}, \mathrm{N}$ & I & I & I \\
\hline & 250 & $\mathrm{~N}$ & I & $\mathrm{I}, \mathrm{N}$ & $\mathrm{I}, \mathrm{N}$ & $\mathrm{N}$ & $\mathrm{N}$ & $\mathrm{I}, \mathrm{N}$ & $\mathrm{I}, \mathrm{N}$ & $\mathrm{N}$ & I & I & $X, Y$ & $\mathrm{I}, \mathrm{N}$ & $\mathrm{I}, \mathrm{N}$ & $\mathrm{N}, \mathrm{I}$ & $\mathrm{I}, \mathrm{N}$ & $\mathrm{I}, \mathrm{N}$ & $\mathrm{I}, \mathrm{N}$ & I & I & I \\
\hline & 500 & $\mathrm{~N}$ & I & $\mathrm{I}, \mathrm{N}$ & $\mathrm{I}, \mathrm{N}$ & $\mathrm{N}$ & $\mathrm{N}$ & $\mathrm{I}, \mathrm{N}$ & $\mathrm{I}, \mathrm{N}$ & $\mathrm{N}$ & I & I & $X, Y$ & $\mathrm{I}, \mathrm{N}$ & $\mathrm{I}, \mathrm{N}$ & $\mathrm{N}, \mathrm{I}$ & $\mathrm{I}, \mathrm{N}$ & $\mathrm{I}, \mathrm{N}$ & $\mathrm{I}, \mathrm{N}$ & I & I & I \\
\hline
\end{tabular}

Samples previously tested with other typing systems yielded promising results with InnoTyper 21. Of 16 samples tested, 12 samples produced InnoTyper 21 results of at least 100 RFU at 5 or more loci (Table 10). The results indicate that InnoTyper 21 can be utilized as a complementary system to STRs to increase the statistical significance of a match. For example, sample UNT22 previously produced a 5-locus STR profile with a genotype frequency of approximately 1 in 3.8 million individuals of the African American population and approximately 1 in 42.9 million individuals of the Caucasian population, while the 17-locus InnoTyper 21 profile produced by this sample has a genotype frequency of approximately 1 in 31.4 million individuals of the African American population and approximately 1 in 169.8 million individuals of the Caucasian population (using $2 \mathrm{pq}$ and $\mathrm{p}^{2}$ ). Figure 9 shows an InnoTyper 21 electropherogram of sample UNT13, a bone sample that previously produced no result with STR testing, and inconclusive result with mtDNA testing. Approximately $10 \mu \mathrm{L}$ of sample UNT13 was amplified with InnoTyper 21 (it should be noted that the final version of the kit allows for the addition of up to $16 \mu \mathrm{L}$ of total input DNA), and results show a 17 -locus InnoTyper 21 profile with an average RFU of 285, and a statistical profile frequency of 1 in 14 billion Caucasians and 1 in 254 million African Americans (using 2pq and $\mathrm{p}^{2}$ ). Results for all remains tested are shown in Table 10. 
Table 10. Results of the analysis of highly degraded human remains previously tested with other typing systems. P/C IC indicates samples were previously tested with Profiler/Cofiler using increased cycle number, MF indicates samples were previously tested with MiniFiler.

\begin{tabular}{|c|c|c|c|c|c|c|c|c|}
\hline \multirow[b]{2}{*}{$\begin{array}{c}\text { Sample } \\
\text { Name }\end{array}$} & \multirow[b]{2}{*}{$\begin{array}{c}\text { Sample } \\
\text { Type }\end{array}$} & \multirow[b]{2}{*}{$\begin{array}{c}\text { Estimated } \\
\text { Age }\end{array}$} & \multirow{2}{*}{$\begin{array}{c}\text { Quantity } \\
\text { Amplified } \\
\text { based on } \\
\text { Quantifiler } \\
\text { Duo (pg) }\end{array}$} & \multicolumn{2}{|r|}{ Previous Results } & \multicolumn{3}{|c|}{ InnoTyper 21 Loci } \\
\hline & & & & MtDNA & Number of STR Loci & $\begin{array}{c}\text { No. of } \\
\text { loci } \\
\text { above } \\
100 \text { RFU }\end{array}$ & $\begin{array}{c}\text { No. of loci } \\
\text { exhibiting } \\
\text { allele } \\
\text { dropout }\end{array}$ & $\begin{array}{c}\text { Average } \\
\text { RFU }\end{array}$ \\
\hline UNT 11 & Tooth & $50-80$ years & Undet. & NR & $\mathrm{PC} / \mathrm{IC}=0$ & 5 & 16 & 756 \\
\hline UNT 12 & Tooth & 50-80 years & Undet. & NR & $\mathrm{PC} / \mathrm{IC}=0$ & 1 & 20 & 517 \\
\hline UNT 13 & Tooth & $50-80$ years & Undet. & Inconclusive & $\mathrm{PC} / \mathrm{IC}=0$ & 18 & 8 & 285 \\
\hline UNT 14 & Tooth & 50-80 years & Undet. & NR & $\mathrm{PC} / \mathrm{IC}=0$ & 0 & 21 & $\mathrm{n} / \mathrm{a}$ \\
\hline UNT 15 & Tooth & 50-80 years & Undet. & NR & $\mathrm{PC} / \mathrm{IC}=0$ & 6 & 15 & 265 \\
\hline UNT 16 & Tooth & $50-80$ years & Undet. & Partial & $\mathrm{PC} / \mathrm{IC}=0$ & 2 & 19 & 181 \\
\hline UNT 17 & Tooth & 50-80 years & Undet. & Partial & $\mathrm{PC} / \mathrm{IC}=0$ & 2 & 20 & 361 \\
\hline UNT 18 & Femur & 23 years & 13.9 & HV1 \& HV2 & $\mathrm{PC} / \mathrm{IC}=0$ & 19 & 3 & 367 \\
\hline UNT 19 & Metacarpal & 42 years & 5.0 & HV1 \& HV2 & $\mathrm{PC} / \mathrm{IC}=0$ & 18 & 3 & 576 \\
\hline UNT 20 & Femur & unknown & Undet. & HV1 \& HV2 & $\mathrm{PC} / \mathrm{IC}=0$ & 16 & 3 & 267 \\
\hline UNT 21 & Femur & unknown & Undet. & HV1 \& HV2 & $\mathrm{PC} / \mathrm{IC}=0$ & 5 & 2 & 134 \\
\hline UNT 22 & Humerus & unknown & Undet. & HV1 \& HV2 & $\mathrm{PC} / \mathrm{IC}=5, \mathrm{MF}=0$, Total $=5$ & 17 & 4 & 366 \\
\hline UNT 23 & Femur & unknown & 16.2 & HV1 \& HV2 & $\mathrm{PC} / \mathrm{IC}=6, \mathrm{MF}=7$, Total $=11$ & 20 & 1 & 721 \\
\hline UNT 24 & Tibia & 41 years & Undet. & HV1 \& HV2 & $\mathrm{PC} / \mathrm{IC}=2, \mathrm{MF}=5$, Total $=7$ & 20 & 1 & 385 \\
\hline UNT 25 & Rib & 5 years & Undet. & HV1 \& HV2 & $\mathrm{PC} / \mathrm{IC}=5, \mathrm{MF}=2$, Total $=6$ & 17 & 4 & 330 \\
\hline UNT 26 & Tibia & 23 years & 39.8 & HV1 \& HV2 & $\mathrm{PC} / \mathrm{IC}=5, \mathrm{MF}=5$, Total $=8$ & 21 & 0 & 487 \\
\hline
\end{tabular}

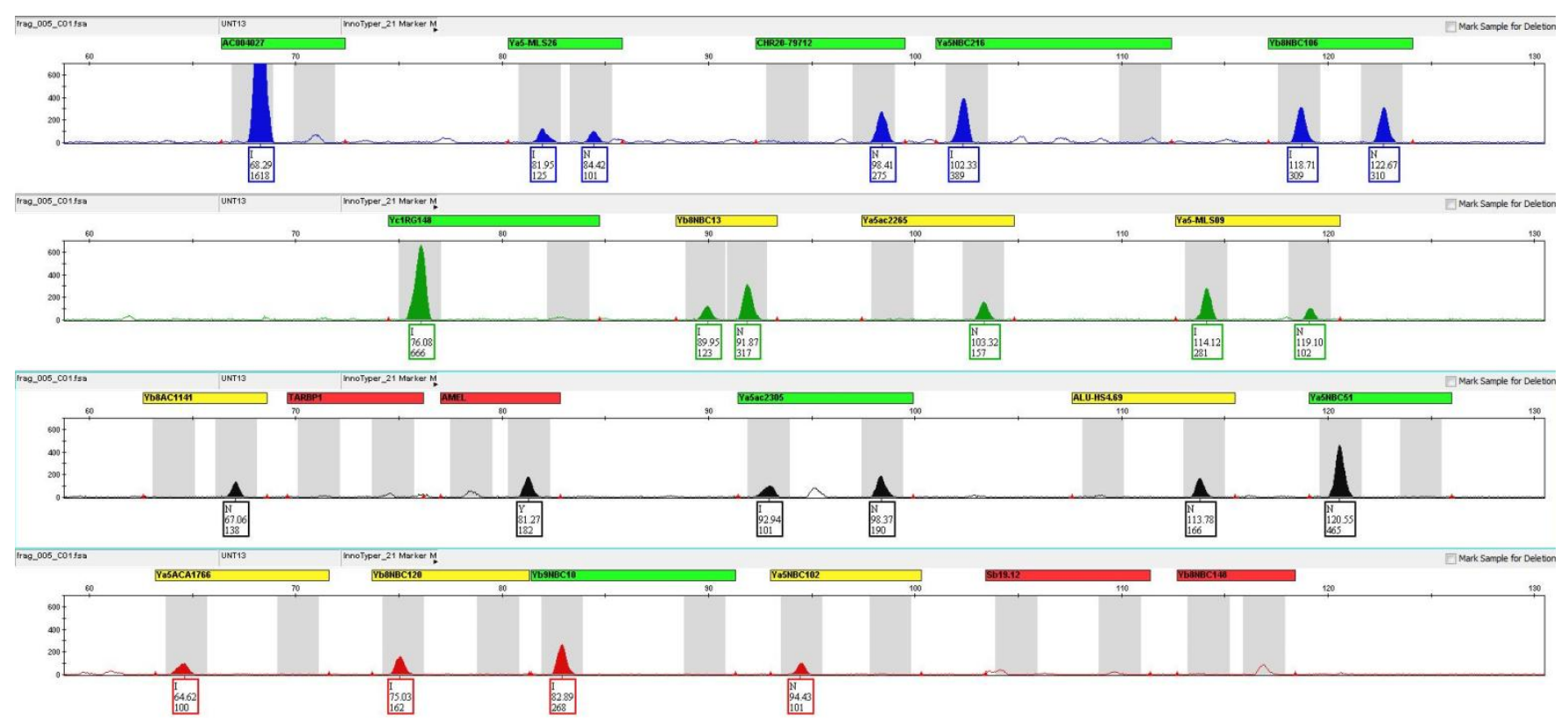

Figure 9. InnoTyper 21 result of 50-80 year old human remains sample UNT13 analyzed at 100 RFU analytical threshold. 
These results indicate that InnoTyper 21 can yield useful nuclear DNA results from challenging samples up to 80 years old that previously produced partial or no results with other typing systems.

\section{Population Database Study}

Five sample populations (African-American, $n=207$; Southwest Hispanic $n=40$; Caucasian, $n=301$ (i.e., US, n= 205; UK, n=96); and East Asian, n = 44) were typed for the InnoTyper 21 loci. The allele frequencies and observed and expected heterozygosity are listed in Table 11. All loci were polymorphic in all five sample populations. Heterozygosity (observed) across the markers and populations ranged from a low of 0.073 for the ALU79712 locus in Asians to a high of 0.65 for the NBC216 locus in Hispanics. The average heterozygosity was similar for all five sample populations. Population parameters for the five groups are provided in Table 12. The power of discrimination (PD) across the populations ranged from a low of 0.136 at the ALU79712 locus in Asians to a high of 0.635 at the SB19.12 locus in Asians. The combined PD for all loci per population was $>0.999$. There were only two departures from HWE expectations detected (at the loci NBC216 (p=0.030) and AC1141 (p=0.007) in the Caucasian population). When the critical value was adjusted by the Bonferroni correction [46], these departures were no longer significant.

Departures from linkage equilibrium [i.e., linkage disequilibrium (LD) between pairs of loci] were tested for each of the five populations. Five pairs of loci in the African-American population, 14 pairs in the Hispanic population, 26 pairs in the UK Caucasians, four pairs in US Caucasians demonstrated, and two pairs in the US East Asian population demonstrated significant LD (at $\mathrm{p}<0.05)$ (Supplemental Table 9). The higher than expected number of apparent LDs in the UK Caucasians could be associated with the deviation from HWE at the two 
loci demonstrating departures from HWE expectations, as described by Falush et al. [47] and

Chakraborty [48] or due to substructure. The former possibility is supported as 13 of the 26 pairs

involved the two loci NBC216 or AC1141. Regardless, when the critical value was adjusted for multiple comparisons (via the Bonferroni correction, 49), only one pair of loci (MLS09/TARBP, $\mathrm{p}=0.002$ ) displayed significant LD.

Wright's F $_{\text {ST }}$ was estimated to assess the population substructure [45]. For the five populations, the $\mathrm{F}_{\mathrm{ST}}$ values are provided for each locus as there are some loci in which the values are relatively high and others in which the values are relatively low (Table 12). For example, the markers AC1141 and NBC148 have $\mathrm{F}_{\mathrm{ST}}$ values $>0.16$, while for marker NBC120 the $\mathrm{F}_{\mathrm{ST}}$ value is 0.0004. These data suggest (consistent with the allele frequency differences in Table 11) that some markers have very different allele frequencies between populations, while others are more similar. Regardless, the overall data support that these population data can be used to assess the rarity of an InnoTyper 21 profile.

Table 11. Population specific InnoTyper 21 allele frequencies and heterozygosity for five major population groups

\begin{tabular}{|c|c|c|c|c|c|c|c|c|c|c|c|c|c|c|c|c|c|c|c|c|}
\hline \multirow[b]{2}{*}{ Locus } & \multicolumn{4}{|c|}{ African American ( $N=207)$} & \multicolumn{4}{|c|}{ Southwest Hispanic $(\mathrm{N}=40)$} & \multicolumn{4}{|c|}{ UK Caucasian (N=96) } & \multicolumn{4}{|c|}{ US Caucasian ( $\mathbf{N}=\mathbf{2 0 5}$ ) } & \multicolumn{4}{|c|}{ East Asian (US) (N=44) } \\
\hline & \begin{tabular}{|c|} 
Insertion \\
Frequency
\end{tabular} & $\begin{array}{c}\text { Null } \\
\text { Frequency }\end{array}$ & $\mathrm{He}$ & Ho & \begin{tabular}{|c|} 
Insertion \\
Frequency
\end{tabular} & \begin{tabular}{|c|} 
Null \\
Frequency
\end{tabular} & $\mathrm{He}$ & Ho & $\begin{array}{c}\text { Insertion } \\
\text { Frequency }\end{array}$ & \begin{tabular}{c|} 
Null \\
Frequency
\end{tabular} & $\mathrm{He}$ & Ho & \begin{tabular}{|c|} 
Insertion \\
Frequency
\end{tabular} & $\begin{array}{c}\text { Null } \\
\text { Frequency }\end{array}$ & $\mathrm{He}$ & Но & \begin{tabular}{|c|} 
Insertion \\
Frequency
\end{tabular} & \begin{tabular}{c|} 
Null \\
Frequency
\end{tabular} & He & Ho \\
\hline the & & & & 0.536 & & & 0 & 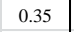 & & & 40 & & & & 9256 & (1 & & & 49897 & \\
\hline & & & & & & & & & & & & & & & & & & & & \\
\hline & & & & 0.43 & & & & & & & & & & & 9981 & 502 & & 6340 & 07052 & \\
\hline & & & & & & & & & & & & & & & & & & & & \\
\hline & & & 3878 & 0.43500 & & & 875 & & & $29 \quad 0$ & & & & & 423 & 512 & & 3864 & 49974 & \\
\hline & & & & & & & & 0.475 & & & & & & & & & & & 1632 & \\
\hline $\mathrm{NBC} 1$ & & 02 & 4298 & 0.33300 & 50 & & 6219 & 0.475 & & 150 & 0.44784 & 0.448 & & & 46403 & 0.488 & 90 & 85710 & 0.24496 & 0.28571 \\
\hline & & & & 0.46400 & & & & 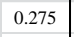 & & & & & & & & 1 & & & & \\
\hline MLS & 0 & 33 & 135 & 0.36700 & 750 & & 7469 & 75 & & $50 \quad 0$ & 0.46875 & & & & 704 & 0.468 & & 450 & 0.28810 & 0.25581 \\
\hline & & & & 0.34300 & & & 9969 & 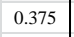 & & & & & & & & 8 & & & 7810 & \\
\hline & & & 5 & 0.37700 & 6250 & & 6219 & & & & & & & & 626 & 0.502 & & 64773 & 0.45635 & 0.47727 \\
\hline & & & 2535 & 0.43000 & 6250 & & 4719 & 0.375 & & & 73 & 0 & & & 49256 & 8 & & 14290 & 24496 & 0.28571 \\
\hline & & & & 0.41500 & & & 2000 & & & & & & & & & 0.459 & & & 0.43077 & 0.48837 \\
\hline NB & 20 & 58 & 225 & 0.45400 & 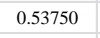 & & 9719 & 5 & & $\begin{array}{ll}9 & 0\end{array}$ & 57 & 0.417 & & & 49957 & 2 & & 47 & 6106 & 0.48837 \\
\hline & & & & 0.39100 & & & & & & & & & & & & 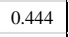 & & & 0.34084 & 0.33333 \\
\hline NB & 660 & 334 & 3134 & 0.46900 & 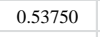 & 25 & 9719 & 5 & & $35 \quad 0$ & 0.48434 & 0.406 & 80 & 2 & 48373 & 459 & & 60714 & 47704 & 0.45238 \\
\hline & & & 4918 & 0.44900 & & & 969 & & & & 0.48240 & & & & 0.49371 & 0.537 & & .74419 & 0.38075 & 0.37209 \\
\hline NBC102 & & 39 & 7841 & 0.45400 & 8750 & & 8469 & 0.425 & & 573 & 0.49343 & 0.594 & & & 0.47589 & 0.459 & & .79550 & .32536 & 0.31818 \\
\hline & & & 7841 & 0.48300 & & & 8875 & & & & 0.41322 & & 980 & & 0.42765 & 0.424 & 463 & 0.58537 & 0.48543 & 0.43902 \\
\hline & & & 0.49622 & 0.51700 & & & 0.15969 & 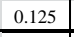 & & & 0.17840 & & & & 0.23588 & 0.237 & & & 0.34421 & 0.34884 \\
\hline $\mathrm{an} \pm 1 \mathrm{~s}$ & $\begin{array}{l}0.43 \pm \\
0.1693 \\
\end{array}$ & & $\begin{array}{c}0.436 \pm \\
0.0655 \\
\end{array}$ & \begin{tabular}{|l|}
$0.43 \pm$ \\
0.0732 \\
\end{tabular} & $\begin{array}{c}0.521 \pm \\
0.1929 \\
\end{array}$ & $\begin{array}{c}0.479 \pm \\
0.1929 \\
\end{array}$ & $\begin{array}{c}0.428 \pm \\
0.092 \\
\end{array}$ & \begin{tabular}{|c|}
$0.413 \pm$ \\
0.1171 \\
\end{tabular} & $\begin{array}{c}0.497 \pm \\
0.1601 \\
\end{array}$ & $\begin{array}{c}0.503 \pm \\
0.1601 \\
\end{array}$ & $\begin{array}{c}0.451 \pm \\
0.0719 \\
\end{array}$ & $\begin{array}{l}0.439 \pm \\
0.0996 \\
\end{array}$ & $\begin{array}{c}0.499 \pm \\
0.1556 \\
\end{array}$ & $\begin{array}{c}0.501 \pm \\
0.1556 \\
\end{array}$ & \begin{tabular}{|l|}
$0.454 \pm$ \\
0.0622 \\
\end{tabular} & $\begin{array}{c}0.458 \pm \\
0.0693 \\
\end{array}$ & $\begin{array}{c}0.481 \pm \\
0.2509 \\
\end{array}$ & $\begin{array}{c}0.519 \pm \\
0.2509 \\
\end{array}$ & $\begin{array}{l}0.38 \pm \\
0.1133 \\
\end{array}$ & $\begin{array}{l}0.39 \pm \\
0.1216 \\
\end{array}$ \\
\hline
\end{tabular}

Ho = Observed Heterozygosity

$\mathrm{He}=$ Expected Heterozygosity

Table 12. Population specific InnoTyper 21 population parameters across five populations 


\begin{tabular}{|c|c|c|c|c|c|c|c|c|c|c|c|c|c|c|c|c|c|c|c|c|c|}
\hline \multirow[b]{2}{*}{ Locus } & \multicolumn{4}{|c|}{ African American (N=207) } & \multicolumn{4}{|c|}{ Southwest Hispanic $(\mathbf{N}=40)$} & \multicolumn{4}{|c|}{ UK Caucasian $(\mathrm{N}=96)$} & \multicolumn{4}{|c|}{ US Caucasian ( $\mathrm{N}=\mathbf{2 0 5})$} & \multicolumn{4}{|c|}{ East Asian (US) (N=44) } & \multirow[b]{2}{*}{$\mathbf{F}_{\mathrm{ST}}{ }^{3}$} \\
\hline & PD & $\begin{array}{c}\text { HWE } \\
(p-\text { value })^{1,2}\end{array}$ & MP & PE & PD & $\begin{array}{c}\text { HWE } \\
\text { (p-value) })^{1,2}\end{array}$ & MP & PE & PD & $\begin{array}{c}\text { HWE } \\
(p-\text { value })^{1,2}\end{array}$ & MP & PE & PD & $\begin{array}{c}\text { HWE } \\
(p-\text { value })^{1,2}\end{array}$ & $M P$ & PE & PD & 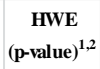 & RMP & PE & \\
\hline AC $402 T$ & 62350 & 26906 & 0.37650 & 0.18675 & 0.59950 & 16031 & 10050 & 0.17574 & 0.61560 & 1.00000 & 8440 & 0.18305 & 0.62120 & 0.77230 & 37880 & 0.18563 & 0.62397 & 00000 & .37603 & 0.18724 & 0.01439 \\
\hline MLS26 & 1210 & 844 & 8790 & 0.11114 & 0.62480 & - & 7520 & 0.18742 & 4780 & 2480 & 5220 & 0.15550 & 5770 & 1070 & 4230 & 0.15913 & 5706 & 4150 & 44294 & 0.18310 & 11799 \\
\hline ALU7971 & 0.58060 & 0.47125 & 0.41940 & 0.16797 & 0.62500 & 0.36031 & 0.37500 & 0.18750 & 0.60470 & 0.30310 & 39530 & 0.17800 & 0.59500 & 00000 & 40500 & 0.17387 & 0.13563 & 0000 & .86437 & 0.03402 & .02807 \\
\hline NBC216 & 0.61510 & 0.17844 & 0.38490 & 0.18275 & 0.62360 & 1.00000 & 0.37640 & 0.18679 & 0.62320 & 0.02950 & .37680 & 0.18663 & 0.62490 & 0.58940 & .37510 & 0.18745 & 0.54638 & 68410 & .45362 & 0.15833 & \begin{tabular}{|l}
0.09887 \\
\end{tabular} \\
\hline NBC106 & 0.61920 & 0.11906 & 0.38080 & 0.18466 & 0.60790 & 0.02531 & 0.39210 & 0.17944 & 0.61950 & 0.39470 & 0.38050 & 0.18481 & 0.62210 & 0.67610 & 0.37790 & 0.18605 & 0.58368 & 0.54270 & 0.41632 & 0.18744 & 0.08016 \\
\hline RG148 & 0.62370 & 1.00000 & 0.37630 & 0.18684 & 0.60390 & 1.00000 & 0.39610 & 0.17769 & 0.59260 & 0.64420 & 0.40740 & 0.17283 & 0.56780 & 0.22560 & 0.43220 & 0.16296 & 0.58264 & 0.14520 & 0.41736 & 0.16483 & 0.03994 \\
\hline $\mathrm{NBC} 13$ & 0.50950 & 0.67656 & 0.49050 & 0.14208 & 0.60390 & 1.00000 & 0.39610 & 0.17769 & 0.59480 & 1.00000 & 0.40520 & 0.17378 & 0.60510 & 0.54490 & 0.39490 & 0.17819 & 0.40816 & 0.58280 & 0.59184 & 0.10748 & \begin{tabular}{|l}
-0.00198 \\
\end{tabular} \\
\hline AC2265 & 0.61230 & 0.77188 & 0.38770 & 0.18145 & 0.52760 & 0.17750 & 0.47240 & 0.14830 & 0.55970 & 0.44320 & 0.44030 & 0.15989 & 0.54430 & 0.36060 & 0.45570 & 0.15422 & 0.43916 & 0.57530 & 0.56084 & 0.11772 & 0.11967 \\
\hline MLS09 & 0 & & 0.4 & 0.14803 & 0.61140 & & 60 & 0.18 & 90 & & 10 & 9944 & 0 & & 3170 & 0.18422 & 0 & & 435 & 0.12330 & .03192 \\
\hline AC1141 & 0.51970 & 0.68969 & 0.48030 & 0.14556 & 0.56760 & 0.68813 & 0.43240 & 0.16288 & 0.61560 & 0.00650 & 0.38440 & 0.18305 & 0.61080 & 1.00000 & 0.38920 & 0.18076 & 0.61871 & 1.00000 & 0.38129 & 0.18190 & 0.16113 \\
\hline TARBP & 0.56600 & 0.30781 & 0.43400 & 0.16225 & 0.60390 & 0.73250 & 0.39610 & 0.17769 & 0.62170 & 0.83800 & .37830 & 0.18585 & 0.61780 & 0.66570 & 0.38220 & 0.18402 & 0.59194 & 1.00000 & 0.40806 & 0.17611 & 0.01745 \\
\hline AC2305 & 0.57930 & 1.00000 & 0.42070 & 0.16744 & 0.59440 & 0.32063 & 0.40560 & 0.17360 & 0.61080 & 0.52090 & 0.38920 & 0.18076 & 0.62120 & 0.88580 & 0.37880 & 0.18563 & 0.40816 & 0.57250 & 0.59184 & 0.10748 & 0.09161 \\
\hline HS4.69 & 0.58570 & 0.52938 & 0.41430 & 0.17001 & 0.48640 & 0.64031 & 0.51360 & 0.13440 & 0.61220 & 0.08650 & 0.38780 & 0.18137 & 0.61080 & 0.66400 & 0.38920 & 0.18076 & 0.56138 & 0.49290 & 0.43862 & 0.16900 & 0.05282 \\
\hline NBC51 & 0.61570 & 0.38625 & 0.38430 & 0.18298 & 0.62360 & 0.52438 & 0.37640 & 0.18679 & 0.62220 & 0.14460 & 0.37780 & 0.18614 & 0.62480 & 0.58070 & 0.37520 & 0.18739 & 0.59167 & 1.00000 & 0.40833 & 0.17739 & 0.08278 \\
\hline ACA1766 & 0.56100 & 0.47844 & 0.43900 & 0.16038 & 0.48640 & 0.51344 & 0.51360 & 0.13440 & 0.62170 & 1.00000 & 0.37830 & 0.18585 & 0.61210 & 0.55500 & 0.38790 & 0.18133 & 0.50756 & 1.00000 & 0.49244 & 0.14138 & 0.03241 \\
\hline NBC120 & 0.61510 & 0.76969 & 0.38490 & 3275 & 0.62360 & s & 640 & 8679 & 0.61680 & 70 & 20 & 3352 & 0.61650 & 0. & 3350 & 0.18337 & 62245 & & .37755 & 0.18163 & .00037 \\
\hline NBC10 & 0.59570 & 1.00000 & 0.40430 & 0.17415 & 0.62480 & 1.00000 & 0.37520 & 0.18742 & 0.61560 & 0.67190 & 0.38440 & 0.18305 & 0.62180 & 0.25110 & 0.37820 & 0.18592 & 0.54516 & 1.00000 & 0.45484 & 0.15413 & 0.03307 \\
\hline NBC102 & 0.61350 & 0.73250 & 0.38650 & 0.18199 & 0.61700 & 1.00000 & 0.38300 & 0.18361 & 0.61220 & 0.06070 & 0.38780 & 0.18137 & 0.60430 & 0.65610 & 0.39570 & 0.17782 & 0.49174 & 1.00000 & 0.50826 & 0.13622 & 0.01929 \\
\hline SB19.12 & 0.61350 & 1.00000 & 0.38650 & 0.18199 & 0.45240 & 1.00000 & 0.54760 & 0.12353 & 0.57030 & 0.21370 & 0.42970 & 0.16392 & 0.58100 & 0.87400 & 0.41900 & 0.16810 & 0.63534 & 0.53320 & 0.36466 & 0.18380 & 0.09632 \\
\hline NBC148 & 0.62310 & 0.57969 & 0.37690 & 0.18655 & 0.28110 & 0.25438 & 0.71890 & 0.07347 & 0.30910 & 1.00000 & 0.69090 & 0.08124 & 0.38830 & 1.00000 & 0.61170 & 0.10403 & 0.51055 & 1.00000 & 0.48945 & 0.14248 & \begin{tabular}{|l}
0.20125 \\
\end{tabular} \\
\hline Overall & $3 \mathrm{E}-05$ & & $2.47 \mathrm{E}-08$ & 0.9757 & $9.59 \mathrm{E}-06$ & & $3.52 \mathrm{E}-08$ & 0.9740 & $2.14 \mathrm{E}-05$ & & 49E-08 & 0.9780 & $2.65 \mathrm{E}-05$ & & $1.34 \mathrm{E}-08$ & 0.9785 & $9.55 \mathrm{E}-07$ & & $2.64 \mathrm{E}-07$ & 0.9626 & 0.06689 \\
\hline
\end{tabular}

$\mathrm{PD}=$ Power of Discrimination

HWE = Hardy Weinberg equilibrium

$\mathrm{RMP}=$ Random Match Probability

$\mathrm{PE}=$ Probability of Exclusion

1. $\alpha$-level of 0.05 is adjusted from 0.05 to 0.0025 when corrected for multiple tests (Bonferroni's correction).

2. Calculated using GDA software [44]

3. Calculated according to Weir BS with GDA [45]

The allele frequencies of the African American and Caucasian data reported herein were similar to those obtained by NIST [50] for the same populations. The allele frequencies for the Hispanics generally were similar but a few loci were notably different, likely due to the different origins of the populations (e.g., U.S. Southwestern Hispanics vs. U.S. Southeastern Hispanics).

Regarding mutation rates, because there is no known mechanism of RE insertions to revert back to native state (i.e., no insertion) and vice versa [13,14], Alus have no reported insertion polymorphism "mutation" [23]. However, a mutation in a primer binding site may cause allele imbalance or complete drop-out of an allele. For this reason, a single InnoTyper 21 discrepancy in a kinship case should not be used as the sole basis to draw a conclusion of exclusion. An in-house study of 94 parentage cases comprising 158 known meiosis revealed no such mutations (data not shown). However, for practical purposes, if an InnoTyper 21 mutation is encountered in a kinship case, it seems reasonable to use the mutation rates of other similar systems, such as SNPs, which are considerably lower than STR mutation rates [51]. 
In addition, the system may exhibit a variant causing the insertion or no insertion allele to size differently than the known sizes, as has been previously observed in InnoTyper 21 as well as other systems [27]. Variant alleles have been observed in the InnoTyper 21 system in markers NBC106, NBC120, and RG148 both in-house as well as by other users [50, non-probative section above, and personal communication]. Virtual bins for those variant alleles confirmed by sequencing have been added to the InnoTyper 21 GMID/GMID-X panel and bin files, described as the number of base pairs larger or smaller than the corresponding ladder alleles (i.e. I-1 or $\mathrm{N}+1$ ). When encountered in both questioned and known samples of a forensic case, these microvariant alleles will increase the power of discrimination. 


\section{Conclusions}

The InnoTyper 21 PCR amplification kit simultaneously amplifies 20 INNUL markers and the sex determining marker Amelogenin, making it a highly discriminating nuclear DNA detection system for human identification. Because the primers for the InnoTyper 21 loci were designed using a strategy that allows small product fragments to be formed (between 63 and 123 bp), degraded samples may yield more typing results with the InnoTyper ${ }^{\circledR} 21$ kit than previously possible with current STR kits. Additionally, the InnoTyper 21 kit is more discriminating than mtDNA sequencing, which until now was one of the few options for characterizing degraded single source samples. Thus, a forensic analyst has alternatives in deciding which typing system to use, especially when confronted with a compromised DNA sample that yields sufficient DNA only for a single analysis.

The validation of the InnoTyper 21 kit encompassed optimization of PCR conditions and reagent concentrations for the amplification of pristine as well as compromised DNA. The performance criteria included overall peak heights, peak height ratios (PHRs), intralocus peak balance, and lack of cross-reactivity in the presence of nonhuman DNA. The PCR conditions and thermal cycling parameters of the InnoTyper 21 kit have been optimized to enhance sensitivity for detection of small amounts of DNA and particularly degraded DNA. The sensitivity studies demonstrated that an input amount of $400 \mathrm{pg}$ of DNA does not produce off-scale peaks and that sufficient signal for complete and almost complete profiles were obtained with $50 \mathrm{pg}$ or less of template DNA.

In summary, the results from the degradation, inhibition and non-probative samples demonstrate that the InnoTyper 21 kit can be extremely useful for amplifying DNA under conditions where other commercial autosomal STR kits often yield partial or no profiles. As such, this kit is a useful and robust complement to conventional STR kits and will be especially 
applicable to challenging cases such as those involving the identification of human remains, hair shafts, paraffin embedded tissues, and other sample types [51-53]. Alu elements are stable polymorphisms with a known ancestral state that are not deleted after being inserted. Alu elements are neutral genetic loci that are poorly transcribed and are identical by descent only, not by state, with no known mechanism for parallel independent insertions to occur, unlike STRs and SNPs. As such, these Alu markers are ideally suited for kinship analysis of degraded human remains.

Finally, while the developmental validation studies have been described herein, it is recommended that each laboratory conduct its own internal validation studies according to FBI Quality Assurance Standards for Forensic DNA Testing Laboratories and/or SWGDAM guidelines [54] and/or applicable standards for each jurisdiction.

\section{Acknowledgements}

This material is based upon work supported by the National Science Foundation under SBIR Grant No. 1230352. Any opinions, findings, and conclusions or recommendations expressed in this material are those of the authors and do not necessarily reflect the views of the National Science Foundation. The authors wishes to express thanks to Dr. Bob Gary, Department of Microbiology, Tulane Health Science Center for DNA samples of non-human DNA used in this research and Dr. Michael Baird, DNA Diagnostics Center for providing DNA samples for database analysis. We express our thanks to Mr. Jonathan Tabak for constructive discussions and editing of this article. 


\section{References}

1. Wang DY, Gopinath S, Lagacé RE, Norona W, Hennessy LK, Short ML, Mulero JJ. Developmental validation of the GlobalFiler ${ }^{\circledR}$ Express PCR Amplification Kit: A 6-dye multiplex assay for the direct amplification of reference samples. Forensic Science International: Genetics, 19 (2015). $148-155$.

2. Ensenberger MG, Lenz KA, Matthies LK, Hadinoto GM, Schienman JE, Przech AJ, Morganti MW, Renstrom DT, Baker VM, Gawrys KM, Hoogendoorn M, Steffen CR, Martín P, Alonso A, Olson HR, Sprecher CJ, Storts DR. Developmental validation of the PowerPlex® Fusion 6C System. Forensic Science International: Genetics, Vol 21, March (2016), Pages 134-144.

3. Parson W, Ballard D, Budowle B, Butler JM, Gettings KB, Gill P, Gusmão L, Hares DR, Irwin JA, King JL, Knijff Pd, Morling N, Prinz M, Schneider PM, Neste CV, Willuweit S, Phillips C. Massively parallel sequencing of forensic STR's: considerations of the DNA commission of International Society of Human Genetics (ISFG) on minimal nomenclature requirements. Forensic Science International Genetics 22 (2016) 54-63.

4. Brinkmann B, Klintschar M, Neuhuber F, Hühne J, Rolf B. Mutation rate in human microsatellites: influence of the structure and length of the tandem repeat. The American Journal of Human Genetics, 62 (1998) p. 1408-1415.

5. Moretti TR, Baumstark AL, Defenbaugh DA, Keys KM, Smerick JB, Budowle B. Validation of short tandem repeats (STRs) for forensic usage: performance testing of fluorescent multiplex STR systems and analysis of authentic and simulated forensic samples. Journal of forensic sciences, (2001) 46(3): p. 647. 
6. LaFountain MJ, Schwartz MB, Svete PA, Walkinshaw, MA, Buel E. TWGDAM Validation of the AmpFlSTR Profiler Plus and AmpFlSTR COfiler STR Multiplex Systems Using Capillary Electrophoresis. Journal of forensic sciences, (2001). 46(5): p. 11911198.

7. Collins PJ, Hennessy, LK, Leibelt CS, Roby RK, Reeder DJ, Foxall PA. Developmental validation of a single-tube Amplification of the 13 CODIS STR Loci, D2S1338, D19S433, and amelogenin: The AmpFlSTR ${ }^{\circledR}$ Identifiler $^{\circledR}$ PCR Amplification Kit. Journal of forensic sciences, (2004). 49(6): p. 1265-1277.

8. Mulero JJ, Chang CW, Lagace’ RE, Wang DY, Bas JL, McMahon TP, Hennessy LK. Development and validation of the AmpFlSTR MiniFiler PCR Amplification Kit: a MiniSTR multiplex for the analysis of degraded and/or PCR inhibited DNA, J. Forensic Sci. 53 July (4) (2008) 838-852.

9. Oostdik K, Lenz K, Nye J, Schelling K, Yet D, Bruski S, Strong J, Buchanan C, Sutton J, Linner J, Frazier N, Young H, Matthies L, Sage A, Hahn J, Wells R, Williams N, Price M, Koehler J, Staples M, Swango KL, Hill C, Oyerly K, Duke W, Katzilierakis L, Ensenberger MG, Bourdeau JM, Sprecher CJ, Krenke B, Storts DR. Developmental validation of the PowerPlex ${ }^{\circledR}$ Fusion System for analysis of casework and reference samples: A 24-locus multiplex for new database standards. Forensic Science International: Genetics, 12, (2014) p. 69-76.

10. Butler JM, Shen Y, McCord BR, The development of reduced size STR amplicons as tools for analysis of degraded DNA. J Forensic Sci. 2003 Sep;48(5):1054-64.

11. Coble M, Butler J. Characterization of new miniSTR loci to aid analysis of degraded DNA. J. Forensic Sci. 50 (1) (2005) 43- 53. 
12. Holland MM, Parsons TJ. Mitochondrial DNA sequence analysis - Validation and use for forensic casework. Forensic Sci Rev 11:21; (1999).

13. Parsons TJ, Muniec DS, Sullivan K, Woodyatt N, Alliston-Greiner R, Wilson MR, Berry DL, Holland KA, Weedn VW, Gill P, Holland MM. A high observed substitution rate in the human mitochondrial DNA control region. Nat Genet 15:363; (1997).

14. Gill P, Werrett DJ, Budowle B, Guerrieri R., An assessment of whether SNPs will replace STRs in national DNA databases--joint considerations of the DNA working group of the European Network of Forensic Science Institutes (ENFSI) and the Scientific Working Group on DNA Analysis Methods (SWGDAM). Sci Justice. (2004) Jan-Mar;44(1):51-3.

15. Batzer MA and Deininger PL. Alu repeats and human genomic diversity. Nature Reviews Genetics, (2002). 3(5): p. 370-379.

16. Batzer MA, Stoneking M, Alegria-Hartman M, Bazan H, Kass DH, Shaikh TH, Novick GE, Ioannou PA, Scheer WD, Herrera RJ. African origin of human-specific polymorphic Alu insertions. Proceedings of the National Academy of Sciences, (1994). 91(25): p. 12288.

17. LaRue BL, Sinha SK, Montgomery AH, Thompson R, Klaskala L, Ge J, King J, Turnbough M, Budowle B. INNULs: A Novel Design Amplification Strategy for Retrotransposable Elements for Studying Population Variation. Hum Hered (2012);74:27-35.

18. Method for genetic detection using interspersed genetic elements, Sinha, Sudhir K. and Carter, Anthony (2010) US Patent \# 7,794,983.

19. Feng Q, Moran JV, Kazazian HH Jr, Boeke JD. Human L1 retrotransposon encodes a conserved endonuclease required for retrotransposition. Cell, (1996) 87(5): p. 905-916. 
20. Houck CM, Rinehart FP, Schmid CW. A ubiquitous family of repeated DNA sequences in the human genome. Journal of Molecular Biology, (1979). 132(3): p. 289-306.

21. Kazazian HH and Moran JV. The impact of L1 retrotransposons on the human genome. Nature Genetics, (1998). 19(1): p. 19-24.

22. Ostertag EM and Kazazian Jr HH. Biology of mammalian L1 retrotransposons. Annual review of genetics, (2001). 35(1): p. 501-538.

23. Ustyugova SV, Amosova AL, Lebedev YB, Sverdlov ED. Cell line fingerprinting using retroelement insertion polymorphism. BioTechniques, (2005) 38(4): p. 561-565.

24. Mamedov IZ, Shagina IA, Kurnikova MA, Novozhilov SN, Shagin DA, Lebedev YB. A new set of markers for human identification based on 32 polymorphic Alu insertions. European Journal of Human Genetics, (2010). 18(7): p. 808-814.

25. Novick GE, Novick CC, Yunis J, Yunis E, Martinez K, Duncan GG, Troup GM, Deininger PL, Stoneking M, Batzer M, Herrera RJ. Polymorphic human specific Alu insertions as markers for human identification. Electrophoresis, (1995). 16(1): p. 15961601.

26. Campbell CD and Eichler EE. Properties and rates of germline mutations in humans. Trends in Genetics, October (2013), Vol. 29, No. 10, p. 575-584.

27. B. Budowle, C. Sprecher. Concordance study on population database samples using the PowerPlex 16 and AmpflSTR Profiler Plus ${ }^{\mathrm{TM}}$ and AmpflSTR COfiler ${ }^{\mathrm{TM}}$ Kit. J. Forensic Sci. 46 (2001) 637-641.

28. Lander ES, Linton LM, Birren B, Nusbaum C, Zody MC, Baldwin J, et al. Initial sequencing and analysis of the human genome. Nature, (2001) 409(6822): p. 860-921.

29. Burger J, Hummel S, Herrmann B, Henke W. DNA preservation: A microsatellite DNA study on ancient skeletal remains. Electrophoresis, (1999). 20(8): p. 1722-1728. 
30. Fondevila M, Phillips C, Naveran N, Cerezo M, Rodriguez A, Calvo R, Fernandez LM, Carracedo A, Lareu MV. Challenging DNA: assessment of a range of genotyping approaches for highly degraded forensic samples. Forensic Science International: Genetics Supplement Series, (2008) 1(1): p. 26-28.

31. Heitzer E, Auer M, Hoffmann EM, Pichler M, Gasch C, Ulz P, et al. Establishment of tumor-specific copy number alterations from plasma DNA of patients with cancer. Int $\mathbf{J}$ Cancer (2013); 133, p. $346-56$.

32. Hughes-Stamm R, Ashton KJ, van Daal A. Assessment of DNA degradation and the genotyping success of highly degraded samples. International journal of legal medicine, (2011) 125(3): p. 341-348.

33. Zangenberg G, Saiki R, Reynolds R. Multiplex PCR: optimization guidelines. PCR applications: protocols for functional genomics. Academic Press, San Diego, CA, (1999): p. 73-94.

34. Budowle B. SNP typing strategies. Forensic Science International, (2004). 146: p. S139.

35. Syvanen AC, Sajantila A, and Lukka M. Identification of individuals by analysis of biallelic DNA markers, using PCR and solid-phase minisequencing. American Journal of Human Genetics, (1993). 52(1): p. 46-59.

36. LaRue BL, Ge J, King JL, Budowle B. A validation study of the Qiagen Investigator DIPplex® kit; an INDEL-based assay for human identification. International journal of legal medicine, (2012): p. 1-8.

37. Shriver MD, Smith MW, Jin L, Marcini A, Akey JM, Deka R, Ferrell RE. Ethnicaffiliation estimation by use of population-specific DNA markers. American Journal of Human Genetics, (1997) 60(4): p. 957. 
38. Wang J, Song L, Grover D, Azrak S, Batzer MA, Liang P. dbRIP: A highly integrated database of retrotransposon insertion polymorphisms in humans. Human Mutation, (2006) 27(4): p. 323-329.

39. Benson DA, Karsch-Mizrachi I, Lipman DJ, Ostell J, Wheeler DL, GenBank. Nucleic Acids Research, (2005) 33(suppl 1): p. D34-D38.

40. Cheung KH, Osier MV, Kidd JR, Pakstis AJ, Miller PL, Kidd KK. ALFRED: an allele frequency database for diverse populations and DNA polymorphisms. Nucleic Acids Research, (2000) 28(1): p. 361.

41. McGinnis S and Madden TL, BLAST: at the core of a powerful and diverse set of sequence analysis tools. Nucleic Acids Research, (2004) 32(suppl 2): p. W20-W25.

42. Untergasser A, Cutcutache I, Koressaar T, Ye J, Faircloth BC, Remm M, Rozen SG (2012) Primer3 - new capabilities and interfaces. Nucleic Acids Research 40(15):e115

43. Pineda GM, Montgomery AH, Thompson R, Indest B, Carroll M, Sinha SK. Development and validation of InnoQuant, a sensitive human DNA quantitation and degradation assessment method for forensic samples using high copy number mobile elements Alu and SVA. Forensic Sci. Int. Genet. 13 (2014) 224-235.

44. Lewis, P.O. and D. Zaykin, Genetic Data Analysis: Computer program for the analysis of allelic data. (2001) Version 1.1, 2001.

45. Weir, B. and C.C. Cockerham, Estimating F-statistics for the analysis of population structure. Evolution, (1984): p. 1358-1370.

46. Weir BS: Multiple tests, In Genetic Data Analysis, Sinauer Associates, Inc., Sunderland, Massachusetts, (1990), pp. 109-110. 
47. Falush D, Stephens M, Pritchard JK: Inference of population structure using multilocus genotype data: linked loci and correlated allele frequencies. Genetics (2003); 164: 15671587.

48. Chakraborty R. Linkage disequilibrium: concept, utility and evolutionary dynamics in the context of the human genome variation. West Lafayette, DESTOBIO 2000.

49. Dunn OJ. Multiple comparisons among means. J Am Stat Assoc1961;56(293):52-64.

50. Villeme A. Bartizal G, Steffen CR, Coble MD. Examination of 20 Retrotransposable Polymorphic Insertion/Null (INNUL) markers for their utility in kinship testing using a commercial software program (LSAM). Poster Presentation B142 at the AAFS Annual Meeting, Las Vegas, NV, February 26, 2016.

51. Campbell CD and Eichler EE. Properties and rates of germline mutations in humans. Trends in Genetics, (October 2013), Vol. 29, No. 10.

52. van den Berge M, Wiskerke D, Gerretsen RRR, Tabak J, Sijen T. DNA and RNA profiling of excavated human remains with varying postmortem intervals. Int J Legal Med DOI 10.1007/s00414-016-1438-9. Published online September 14, 2016.

53. Sinha S, Murphy G, Brown H, Montgomery A, Carrol M, Tabak J. Retrotransposable elements: Novel and sensitive DNA markers and their application in human identity. Forensic Sci. Int.: Genet. Suppl. Ser. 5 (2015) e627-e629.

54. Scientific Working Group on DNA Analysis Methods Validation Guidelines for DNA Analysis Methods. December (2012) http://media.wix.com/ugd/4344b0_cbc27d16dcb64fd88cb36ab2a2a25e4c.pdf 